\title{
Potential for residual load balancing of a frozen food manufacturing plant - a heuristic approach
}

\author{
Authors: Tobias Naegler ${ }^{\mathrm{a},}$, Sonja Simon ${ }^{\mathrm{a}}$ \\ ${ }^{\mathrm{a}}$ German Aerospace Center (DLR), Institute of Engineering Thermodynamics, Department of Systems Analysis \\ and Technology Assessment (TT-STB), Pfaffenwaldring 38-40, 70569 Stuttgart, Germany \\ *corresponding author (tobias.naegler@dlr.de)
}

Keywords: demand response, demand side management, feed-in management, industrial heating and cooling, intermittent renewable energies

\begin{abstract}
We simulated the potential of a frozen food manufacturing plant to contribute to the balancing of the residual load under the premise that the plant's production processes remain unaffected. The plant's technical balancing options comprise both demand side management (chillers for process cold, electric process heat generation) and dispatchable power generation (by a combined heat and power (CHP) plant). In the model, the decoupling of useful energy demand (heat and cold) from power consumption and power generation was enabled by the use of a high temperature thermal energy storage (HT-TES), a cold thermal energy storage (C-TES), and flexible cold storage warehouse temperatures. The analysis shows that the balancing potential basically depends on two factors: (1) plant operation (reflected by gross power demand and power generation) in the inflexible reference case, which defines to which extend power demand and generation can be increased or reduced when the plant is operated flexibly, and (2) the capacity of the thermal energy storages (TES) relative to the typical length of deficit and surplus periods. The model further shows that a heuristic algorithm controlling the operation of the plant's flexible units can exploit a large fraction of the technical balancing potential of the plant.
\end{abstract}

\section{Introduction}

With stricter global targets on reducing GHG emissions [1] strategies for the expansion of renewable energy (RE) supply gain importance [2]. Non-dispatchable sources of renewable power such as wind and photovoltaics (PV) lead the RE expansion in the power sector [3] and are expected to provide the backbone of RE power generation in the future [4], [5], [6]. As a consequence, balancing options for intermittent energy supply become increasingly relevant [7], [8]. The balancing potential of technologies such as power storage, long-range load and generation balancing via the electric grid, flexibilisation of heat-driven combined heat and power (CHP) plants, or demand side management (DSM) are intensively discussed in the scientific literature ([9], [26], [10], [11], [12], [13], [14], [15], [16], [17]): For Germany balancing and storage demand is expected to sharply grow in the early 2020s, when a RE share in gross power generation of more than $40 \%$ is expected [18], [19]. Up to now various studies have proven the potentials of demand side management for balancing intermittent energy supply [20], [21], in particular also in the industry sector [22]. Due to the variety of industrial processes [23], DSM potentials largely depend on the specific local applications in companies. [24] demonstrated this high variability of load and supply on a regional disaggregation for Germany, suggesting that an analysis of industrial management potentials is required on local level. 
Industrial demand side management often relies on preponing or postponing production processes in order to adapt power demand to power system requirements. However, as e.g. [25] points out, thermal energy storages (TES) can temporally decouple useful energy demand (in particular process heat or process cold) from power consumption. TES thus allow industrial demand side management without any change in production quantities or production schedules.

In frozen food manufacturing plants ("FFM plants") generally several thermal processes such as cooking and cooling take place which can principally be flexibilised through TES to allow demand side management. E.g. [26], [27], and [28] have identified a significant DSM potential in refrigeration systems, where the thermal inertia of the cooled goods acts as thermal energy storage. In contrast to this "passive" flexibilisation of process cold generation, TES at temperatures below $0^{\circ} \mathrm{C}$ [34] can technically decouple cold demand for deep freezing from chiller operation. And finally, process heat demand and process heat generation (e.g. in a CHP unit or an electric heater) can be decoupled by a high temperature TES [31], allowing both DSM with the electric heater and a power driven operation of the CHP unit. These considerations illustrate that it is worth investigating the load balancing potential (potential for DSM and power driven operation of CHP units) of a FFM plant in detail in the following paper.

\section{Research focus}

Thus the paper addresses this research gap by presenting the first comprehensive simulation of technical load balancing potentials of a frozen food company, taking into account the complex interplay between heat and cold demand and generation at different temperature levels, thermal energy storage, as well the utilisation and upgrade of waste heat. The analysis is distinguished from previous studies in that it is based on realistic production process description and load time series for useful energy demand from an existing FFM plant in Rheine in Northwest Germany. Furthermore, it assesses not only technical load balancing potentials, but considers restrictions due to the plant's production schedules, which are assumed to remain unchanged by the load balancing. Finally, the study addresses for the first time the load balancing potential of a FFM plant in a local power supply system dominated by high shares of intermittent generation.

The focus of our research in this paper is manifold: First, what is the potential of the FFM plant for balancing local power generation deficits and surpluses in a hypothetical local energy system dominated by intermittent renewable energies? Second, how does the balancing potential of the FFM plant depend on the technical infrastructure of the plant, i.e. on electric loads, power production, and thermal energy storages (TES)? How does the necessary storage capacity depend on the length spectrum of deficit and surplus periods? How do the fixed production processes limit the balancing potential of the plant? And finally: Can the FFM plant's balancing potential be determined with a heuristic algorithm for the operation of the plant's flexible loads, flexible power generation and flexible operation of TES?

We restricted this study to the analysis of technical aspects of the load balancing potential. Economic aspects - such as additional investment of the flexibilisation and additional operation and maintenance (O\&M) costs for flexible operation - are only taken into account as restrictions due to space limitations (to install e.g. TES or heat exchangers) at the plant site etc.

\section{Methodology}

First we describe the principal system applications as well as limits of flexibility of the represented FFM plant. Section 2.2 then describes the model representation within the 
simulation tool INSEL, including data input. Section 2.3 covers the operation algorithms of the simulations.

\subsection{Main processes in the FFM plant and their flexibilisation}

The FFM plant model represents the main processes of the plant according to Figure 1. Many of these processes can be operated in a flexible manner, as thermal energy storages (TES) decouple useful energy demand (heat or cold) and power consumption (resp. power generation). This allows a flexible operation of the heat and cold generation units independent of useful energy demand. Consequently, production schedules are not affected by the flexible operation of these units.

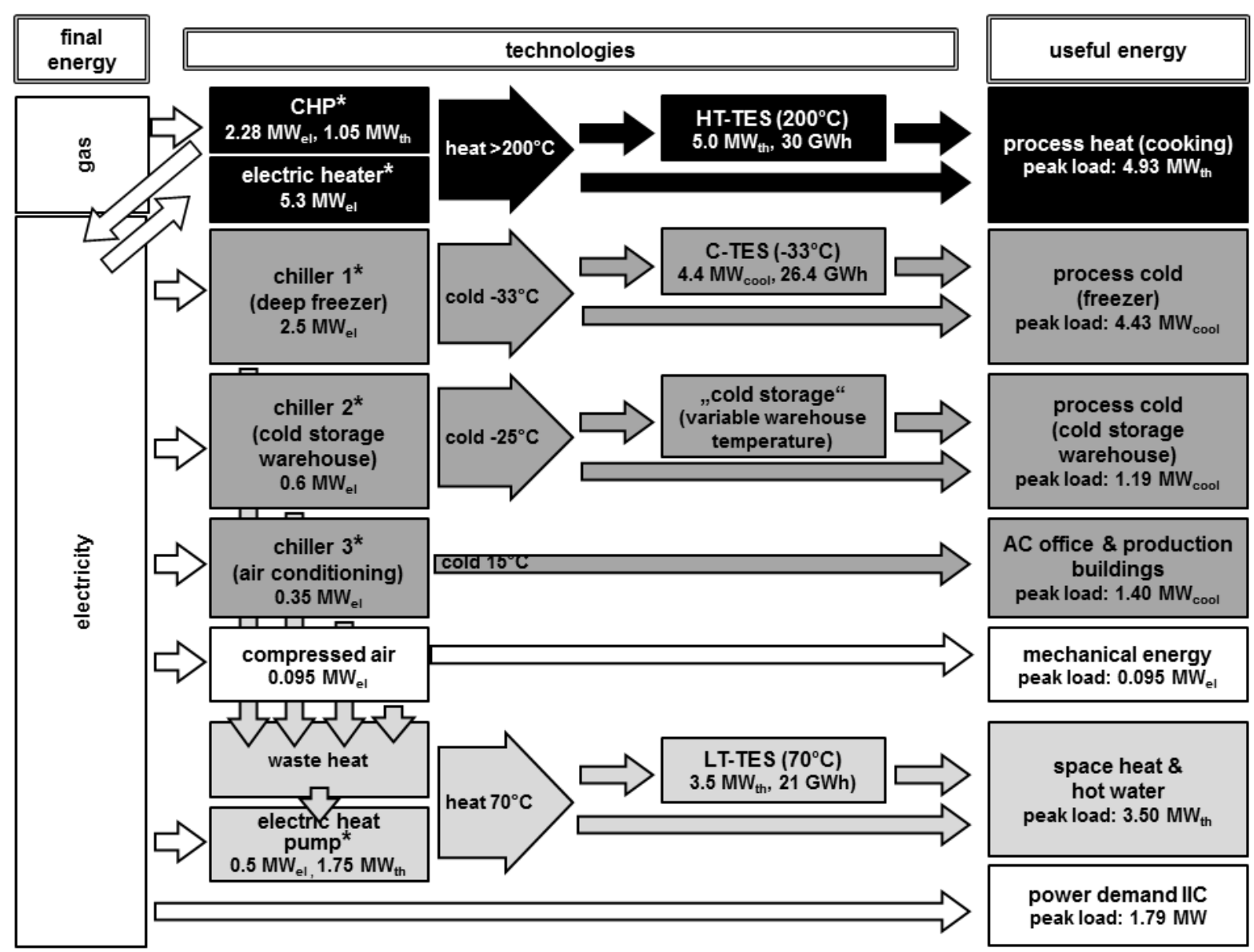

Figure 1: Model structure, main technical model parameters and energy flows of electricity, heat, and gas (Acronyms are explained in the text). All technologies marked with an asterisk $\left(^{*}\right)$ can be run in a flexible manner.

The following processes are included in this integrated system:

\section{Cooking:}

The major energy consumer of the model FFM plant is the cooking of convenience food. In the standard setup of the model a cogeneration unit (a high temperature gas fuel cell, see e.g. [29], [30]) provides baseload process heat for the cooking processes; additionally, an electric heater provides peak load process heat. Alternative process heat technologies have been taken into account in sensitivity tests (see section 2.4). 
The cogeneration unit can be flexibly operated, if heat from cogeneration is stored in a hightemperature thermal energy storage (HT-TES) at times of a high power generation deficit in the municipality and low process heat demand in the FFM. In turn, the HT-TES can provide process heat at times of generation surpluses in the municipality when power cogeneration therefore is shut off..

The electric heater (in combination with the same high-temperature thermal energy storage) provides additional flexibility: In times of a municipal power surplus, the electric heater generates high temperature heat. If no process heat is required at these times, the high temperature heat can be used to charge the TES.

\section{Deep freezing:}

The freshly cooked food is frozen immediately after leaving the kitchen. It is cooled down from approx. $+70^{\circ} \mathrm{C}$ to $-24^{\circ} \mathrm{C}$ within 60 to 90 minutes.

Electricity demand of the deep freezer unit can be decoupled from the production schedule by a cold thermal energy storage (C-TES). It is charged in times of municipal power generation surplus and provides process cold at times of a municipal generation deficit.

\section{Cold warehouse:}

After freezing, the food is stored in a cold storage warehouse at a temperature of $-22^{\circ} \mathrm{C}$ until delivery. Process cold for deep freezing and the cold storage warehouse is provided by two compression chillers.

Temperature within the cold storage warehouse may vary between $-20^{\circ} \mathrm{C}$ and $-24^{\circ} \mathrm{C}$. The thermal capacity of the cold storage warehouse (and its content) serves as a cold storage. During municipal power surplus situations, the cold storage warehouse can be cooled down below the default temperature $\left(-22^{\circ} \mathrm{C}\right)$. During power deficit situations, cold storage warehouse cooling is shut off until inside temperatures reach $-20^{\circ} \mathrm{C}$.

\section{Mechanical energy:}

The system includes a compressed air system, providing mechanical energy (for the band conveyors, automatic packing machines etc.) and producing waste heat, which can be tapped for heat supply (see below). The compressed air system is not a flexible in the model.

\section{Air conditioning (AC) and space heating:}

Office and production buildings are air conditioned in summer and heated in winter in order to keep inside temperatures between $+20^{\circ} \mathrm{C}$ and $+22^{\circ} \mathrm{C}$ during working hours. Climate cold is provided by a third compression chiller, which is operated in a non-flexible way. Space heat is provided by waste heat (see below).

\section{Hot water demand:}

Cleaning of kitchens and cooking equipment require large amounts of hot water (additional to the hot water demand for sanitary purposes). Hot water is provided by waste heat (see below).

\section{Waste heat recovery and upgrading:}

In the model a large fraction of the low temperature heat demand (space heating, hot water) can be covered by waste heat recovery from the chillers (from desuperheaters, compressors and condensers) and from the compressed air unit (see Figure 1). An electric heat pump can upgrade low-temperature waste heat from the chillers' compressors from ca. $30^{\circ} \mathrm{C}$ to $70^{\circ} \mathrm{C}$ (the minimum temperature required for space heat and hot water). A low-temperature thermal energy storage (LT-TES) can decouple waste heat upgrading from lowtemperature heat demand, so that the electric heat pump can be operated in a flexible manner. 


\section{Electricity demand for information, illumination, and communication (IIC):}

Finally, electricity demand for information, illumination and communication (IIC) is also taken into account in the model. This component of the plant's power demand cannot be flexibilised.

\section{Thermal energy storages allow decoupling of useful and final energy demand}

In order to allow for a flexibilisation of the FFM plant's power demand, it is necessary to temporally decouple useful energy demand and final energy consumption (respective process heat production). For this purpose, the model includes high temperature thermal energy storage (HT-TES) for process heat at $200^{\circ} \mathrm{C}$, a low temperature thermal energy storage (LTTES) for upgraded waste heat at $70^{\circ} \mathrm{C}$ (for space heat and hot water) and a cold thermal energy storage (C-TES) for the deep freezer at $-33^{\circ} \mathrm{C}$ (see Figure 1). Technical details of specific TES types are not taken into account in the model. However, in reality, the model's HT-TES could e.g. be a latent heat storage [31] or a sensible heat storage using solids [32]. The LT-TES is well-insulated hot water tank storage. Today, C-TES systems at temperatures above freezing point are mainly used for air conditioning (see e.g. [33]). However, similar physical principles as for HT-TES - sensible heat or latent heat storage - are possible for CTES with operating temperatures well below $0^{\circ} \mathrm{C}$ ([34], [35]), although not commercially available today.

In the standard setup of the model (see Figure 1), the storage capacity (in MWh) for HT-TES and C-TES allow providing $6 \mathrm{~h}$ of the peak demand for cooking and deep freezing. The HTTES charging capacity (in $\mathrm{MW}_{\text {th }}$ ) corresponds to the heat production of the electric heater running under nominal capacity; the HT-TES is also capable of taking up the CHP heat production under full load. When discharging, the HT-TES can provide peak process heat. In a similar manner, charging and discharging capacities of the C-TES (for deep freezing) are adapted to the nominal capacity (cold output) of the chiller for deep freezing and the peak cold demand for deep freezing.

A more detailed model description can be found in the Supplementary Material, where annual useful energy demand, load time series for process heat demand, process cold demand etc. (Section A3) as well as main model parameters and equations (Section A4) are documented.

\subsection{Principal structure within the INSEL simulation environment}

Simulations of FFM plant's flexibility options have been performed with INSEL (see http://www.insel.eu). INSEL is a modular simulation environment particularly developed for simulating energy systems [36]. It combines a general-purpose graphical programming language with a broad library of existing blocks representing different power, heat and infrastructure technologies as well as meteorological parameters. INSEL also provides flexible options to include own technologies or control modules as blocks in the code. INSEL has been used for a variety of analyses in the energy context, e.g. for the simulation of desalination plants driven by renewable energies [37][38].

The newly developed INSEL model for the FFM plant comprises three major component types:

\section{- Exogenously defined model input:}

o Load curves of useful energy demand for process heat, process cold (deep freezer), hot water, pressurised air, and power demand for IIC (see section A3) 
o Time series of the residual load of the municipality (see section A2) which is to be balanced by the FFM plants flexibility options and thus used to trigger the dispatch of these technologies

o Time series required to endogenously calculate useful energy demand for heating and cooling of the office and production buildings and the cold storage warehouse. These time series include ambient temperatures, hours of sunshine etc.

o Technical parameters of the FFM plant's building envelope

o Initial system status for storage filling levels, building temperatures etc.

- Control modules controlling the dispatch of the flexible consumers, dispatchable generation and TES technologies (see section 2.3 for details).

- Technology modules describing the main technical components of the FFM plant's energy supply system (e.g. heat and cold production, energy storage, see section 2.1). Individual technologies are described in a simplified manner by linear equations (main technology equations and parameters are documented in section A4).

The model performs hourly step-by-step simulations for 8760 hours within one year based on the exogenous input described above. The principal model steps at each time steps are:

i. $\quad$ Read exogenously defined quantities (see above).

ii. Read those results from previous time steps which are necessary for the calculations of the actual time step (e.g. storage filling levels, building temperatures ... Those quantities have to be exogenously defined for the first time step of the simulations.).

iii. Determination of operation (provision of useful energy) of all flexible units (flexible chillers, dispatchable power and heat generation units, and thermal storages) by the control modules in order to (a) meet useful energy demand and (b) contribute to the smoothing of the local residual load.

iv. Calculation of final energy demand (power and gas) of flexible consumers and dispatchable generation units according unit dispatch decisions.

v. Calculation of new filling levels for thermal storages according to unit dispatch decisions.

\subsection{Operation algorithms for the flexible units}

Within the control modules, the operation of all flexible units is determined by heuristic operation algorithms presented here in this section.

The operation algorithms for the flexible units are triggered by the local residual load (see Section A2 for details). The operation algorithms distinguish between three typical situations with respect to the residual load (RL):

(1) high local generation surplus (or just "surplus" in the following text): RL is negative and below (negative) threshold $\mathrm{Thr}_{\text {sur: }}$ :

$\mathrm{RL}<\mathrm{Thr}_{\text {sur }}<0$

(2) high local generation deficit (or just "deficit" in the following text): RL is positive and above (positive) threshold $\mathrm{T}_{\text {def: }}$ :

$0<\mathrm{Thr}_{\mathrm{def}}<\mathrm{RL}$

(3) intermediate: $\mathrm{RL}$ is positive or negative, but between $\mathrm{Thr}_{\text {sur }}$ and $\mathrm{Thr}_{\text {def }}$ :

$\mathrm{Thr}_{\mathrm{sur}}<\mathrm{RL}<\mathrm{Thr}_{\mathrm{def}}$

In the following text, intermediate situations - although the residual load might be positive or negative - are not denoted as "deficit” or "surplus" situations.

In the model the operation of the flexible units depends on the residual load; it takes into account a perfect foresight of 12 hours. All flexible technologies are in principle operated in a similar manner: Flexible generation in combination with storage allows always providing the 
necessary process heat or process cold demand. During surplus situations, flexible consumers are run at nominal capacity. Power generation is shut off. Surplus heat or cold is stored. During deficit situations, flexible consumers are shut off, while the CHP runs at maximum capacity. Remaining heat or cold demand is provided by the storages.

A perfect foresight of 12 hours means that the thermal energy storages are "prepared" already 12 hours before a high surplus/high deficit situation in order to allow maximum balancing at the time of the respective event. In the standard model setup, storage capacities (HT-TES and C-TES) are sufficient to provide $6 \mathrm{~h}$ of heat or cold peak demand. In the standard setup of the model, the storage capacity of the TES is set to $6 \mathrm{~h}$. At a foresight capacity of $12 \mathrm{~h}$, the emptying of the storages in the case of an expected high local generation surplus can follow the heat demand and does not have to happen "brute force", i.e. with maximum discharging capacity without the respective heat demand.

The following paragraphs describe the flexible operation and interplay of the technologies providing process heat (CHP unit, electric heater and high-temperature thermal energy storage HT-TES). The operation of these technologies is also illustrated by Figure 2. The flexible operation strategies for the cold storage warehouse, the deep freezer and space heat and hot water supply are summarised in Table 1 and described in detail in Section A5 in the Supplementary Material.

In intermediate situations, the CHP, the electric heater and the HT-TES are operated as follows:

- In case of a small local generation deficit $\left(0<\mathrm{RL}<\mathrm{Thr}_{\mathrm{def}}\right)$ : The cogeneration provides (baseload) process heat, the electric heater supplies peak demand.

- In case of a small local generation surplus ( $\left.\mathrm{Thr}_{\text {sur }}<\mathrm{RL}<0\right)$ : The cogeneration unit is shut off; the entire process heat is provided by the electric heater.

Before a high surplus situation: The cogeneration unit is shut off; process heat is provided by the HT-TES and - if the storage is empty - by the electric heater.

During a high surplus situation: The cogeneration unit is (still) shut off, the electric heater operates with nominal capacity. Surplus high temperature heat (heat production minus heat demand for cooking purposes) is stored in the HT-TES.

Before a strong deficit situation: The cogeneration unit and the electric heater run at nominal capacity. Excess heat is fed into the HT-TES.

During the strong deficit situation: The cogeneration unit runs at nominal capacity. Process heat is provided by the cogeneration unit and - if necessary - by the HT-TES. The electric heater is operating only if process heat demand cannot be provided by the cogeneration unit and the HT-TES.

Note that this heuristic dispatch algorithm is no optimisation in the mathematical sense that the minimum or maximum of an objective function is found (e.g. variability of the residual load after balancing, minimum system costs and/or $\mathrm{CO}_{2}$ emissions as e.g. in [39], [40], [41][42]). 
Table 1: Overview over operation strategies for the plant's flexible components; $\mathrm{PH}$ : process heat, PC: process cold, LTH: low temperature heat (space heat \& hot water), $\mathrm{T}_{\mathrm{WH}}$ : cold storage warehouse temperature. For more details see sections 2.3 and A5.

\begin{tabular}{|c|c|c|c|c|c|c|c|c|c|}
\hline \multirow[b]{2}{*}{ 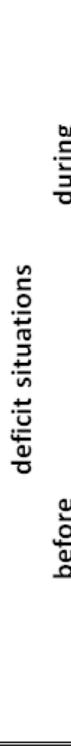 } & 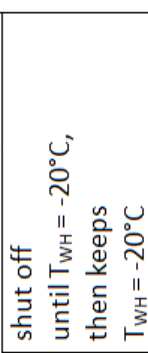 & 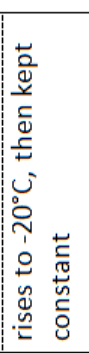 & 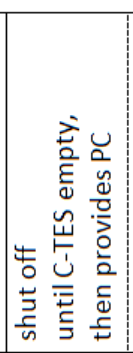 & 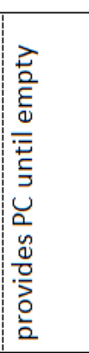 & 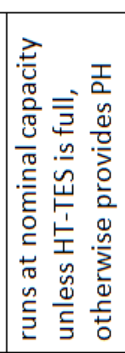 & \begin{tabular}{|l} 
\\
\\
$\frac{4}{2}$ \\
$\frac{4}{2}$ \\
$\frac{5}{n}$ \\
\end{tabular} & 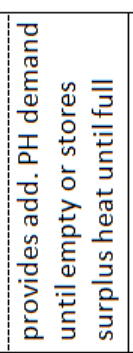 & 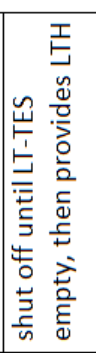 & 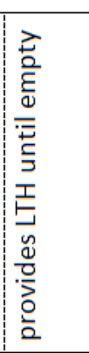 \\
\hline & 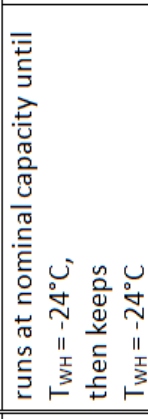 & 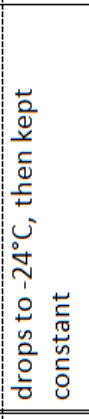 & 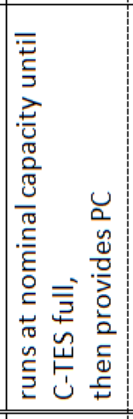 & 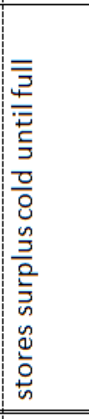 & 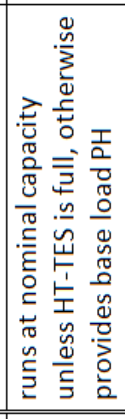 & 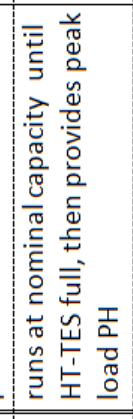 & 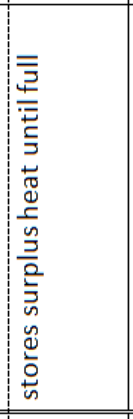 & 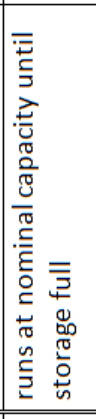 & 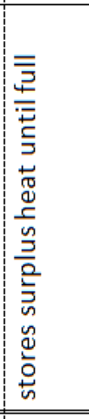 \\
\hline \multirow{2}{*}{ 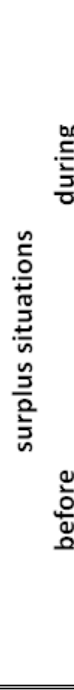 } & 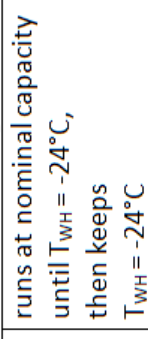 & 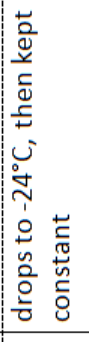 & 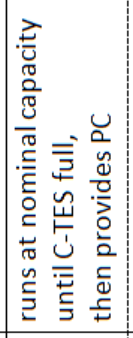 & 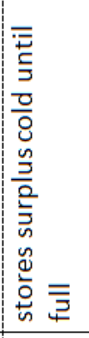 & $\begin{array}{l}\frac{4}{0} \\
0 \\
\frac{3}{2} \\
\frac{1}{n}\end{array}$ & 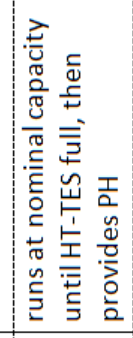 & 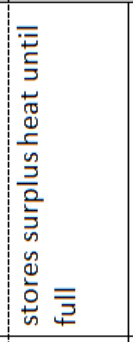 & 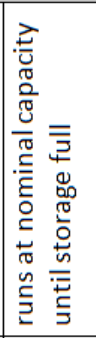 & 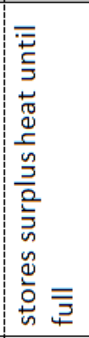 \\
\hline & 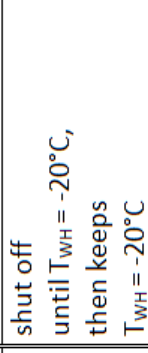 & 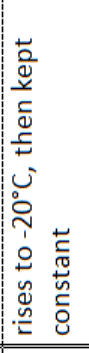 & 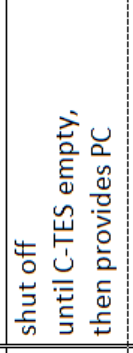 & 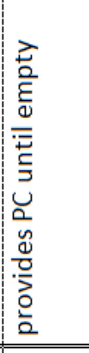 & $\begin{array}{l}\frac{4}{0} \\
0 \\
\frac{1}{3} \\
\frac{5}{5} \\
\end{array}$ & 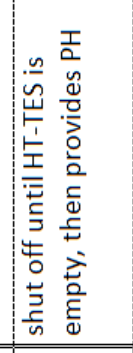 & 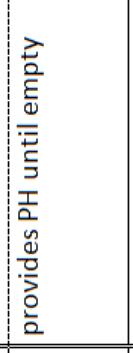 & 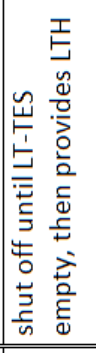 & 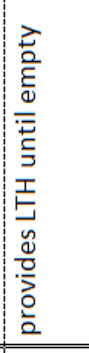 \\
\hline 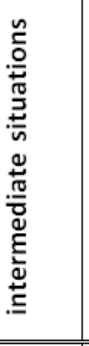 & 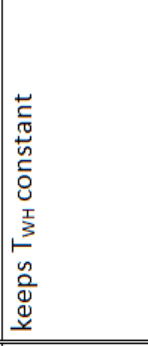 & 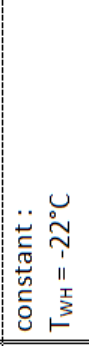 & 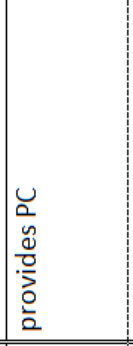 & $\underline{\underline{0}}$ & 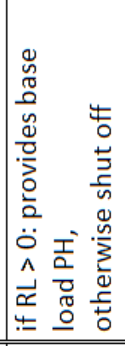 & 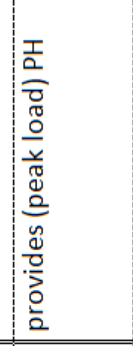 & $\stackrel{0}{0}$ & 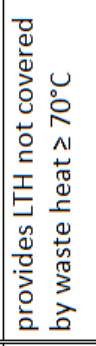 & $\frac{\varrho}{0}$ \\
\hline & 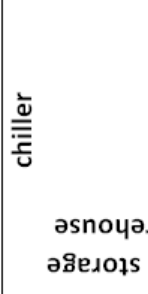 & 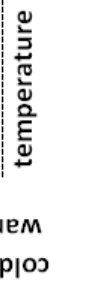 & 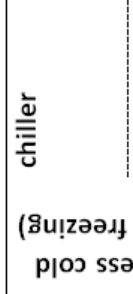 & $\begin{array}{l}\text { Uं } \\
\text { dəəp) } \\
\text { əวoגd }\end{array}$ & 尌 & 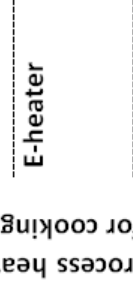 & \begin{tabular}{|l}
$\stackrel{\leftrightarrow}{\mid}$ \\
\end{tabular} & 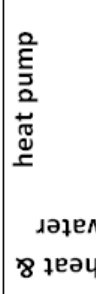 & 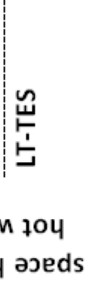 \\
\hline
\end{tabular}




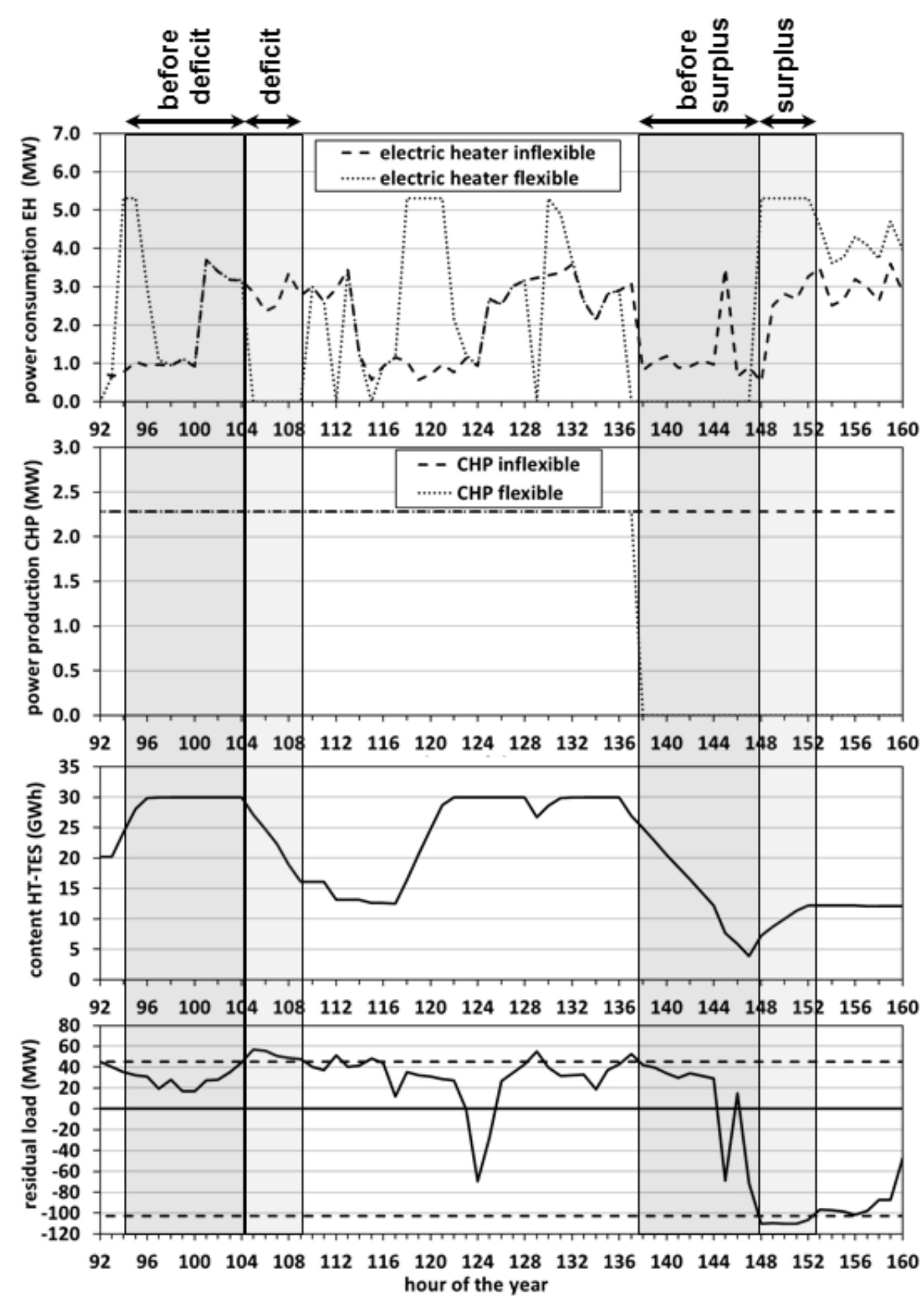

Figure 2: Illustration of the flexible process heat supply in deficit and surplus situations. Top panel: power consumption electric heater, second panel from top: power generation CHP, second panel from bottom: filling level of HT-TES, bottom panel: residual load. See text for further explanations.

\subsection{Characterisation of the different simulations}

In order to assess the technical balancing potential (definition see below) of the FFM plant, we performed a basic set of simulations INFLEX and STD (see next paragraph) as well as 
sensitivity tests on the effects of storage capacity and different structures of the residual load (who differ in terms of frequency and typical duration of deficit and surplus situations). The main parameters characterising these simulations are summarised in Table 2.

\section{Basic simulations}

We performed two basic simulations in order to assess FFM plant's balancing potential:

- INFLEX: The INFLEX simulations provide the baseline against which balancing potentials are assessed. Power demand and generation at the FFM plant are not flexible. INFLEX is characterised by heat-controlled operation of the CHP and the electric heater and cold-controlled operation of the chillers for freezing and cooling of the warehouse at $-22^{\circ} \mathrm{C}$. HT-TES and C-TES are thus not necessary. As long as waste heat is available the heat pump supplies the low temperature heat demand.

- STD: All flexible technologies (process heat generation, deep freezing, cold storage warehouse, waste heat upgrading) are run in order to reduce strong deficit and surplus situations, respectively. Storage capacities (HT-TES, C-TES) are set to 6h. The operation of the flexible technologies is triggered by the residual load STD (see Section A2 and Figure A 1). Very strong generation surplus (residual load $<-110$ MW) is curtailed. The residual load balancing thresholds $\mathrm{Thr}_{\text {sur }}$ and $\mathrm{Thr}_{\text {def }}$ are set to $103 \mathrm{MW}$ and $+45 \mathrm{MW}$, respectively.

Table 2: Overview over main parameters of the different simulation runs

\begin{tabular}{|c|c|c|c|c|c|c|c|c|}
\hline run name & 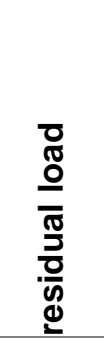 & 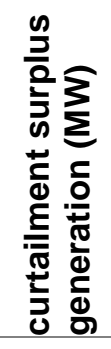 & 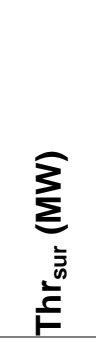 & 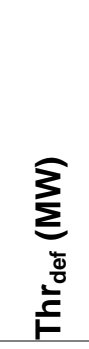 & 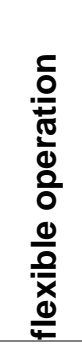 & 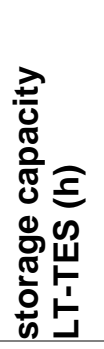 & 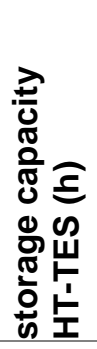 & 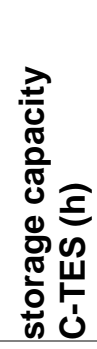 \\
\hline \multicolumn{9}{|c|}{ basic simulations } \\
\hline INFLEX & n.a. & n.a. & n.a. & n.a. & no & n.a. & n.a. & n.a. \\
\hline STD & STD & -110 & -103 & +45 & yes & 6 & 6 & 6 \\
\hline \multicolumn{9}{|c|}{ sensitivity test 1 : storage size } \\
\hline STOR_1h & STD & -110 & -103 & +45 & yes & 6 & 1 & 1 \\
\hline STOR_3h & STD & -110 & -103 & +45 & yes & 6 & 3 & 3 \\
\hline STOR_6h (=STD) & STD & -110 & -103 & +45 & yes & 6 & 6 & 6 \\
\hline STOR_12h & STD & -110 & -103 & +45 & yes & 12 & 12 & 12 \\
\hline STOR_24h & STD & -110 & -103 & +45 & yes & 24 & 24 & 24 \\
\hline STOR_48h & STD & -110 & -103 & +45 & yes & 48 & 48 & 48 \\
\hline STOR_96h & STD & -110 & -103 & +45 & yes & 96 & 96 & 96 \\
\hline STOR_192h & STD & -110 & -103 & +45 & yes & 192 & 192 & 192 \\
\hline \multicolumn{9}{|c|}{ sensitivity test 2: structure of the residual load } \\
\hline AltRL & AltRL & -110 & -103 & +75 & yes & 6 & 6 & 6 \\
\hline
\end{tabular}

The additional sensitivity tests covered two major aspects: 


\section{Sensitivity test 1: storage capacity}

In order analyse the effect of the storage capacity on the balancing potential, we performed sensitivity tests with different storage capacities (for HT-TES, LT-TES and C-TES). While the standard setup assumes a storage capacity of $6 \mathrm{~h}$, we performed additional runs with identical parameterisation to the STD simulation (see above), except for the storage capacities.

- STOR_1h: storage capacity 1h (exception: LT-TES: 6h)

- STOR_3h: storage capacity 3h (exception: LT-TES: 6h)

- STOR_6h: storage capacity 6h (identical with STD)

- $\quad$...

- STOR_192h: storage capacity 192h

The thermal inertia and thus the storage capacity of the cold storage warehouse remain unchanged in all runs. The storage capacity of LT-TES is 6h in STOR_1h and STOR_6h, because otherwise the low temperature heat demand cannot be provided by waste heat during each simulation hour. In the simulations STOR_6h ... STOR_192h, the capacity of LT-TES increases as described above.

\section{Sensitivity test 2: structure of the residual load}

The structure of the residual load, particularly the frequency and length of "strong surplus" and "strong deficit" situations is expected to affect the balancing potential in the case of a limited storage capacity. Therefore the second test analyses the effect of two different residual load scenarios which differ in terms of the frequency and typical duration of surplus and deficit situations (see section A2 and Figure 6).

As discussed in Section A2, the structure of the local residual load may differ significantly depending on the local energy supply concept (see also Figure A 1). We thus performed the following additional simulation:

- The run AltRL switches to an alternative residual load from the supply concept AltRL (see Section A2). Curtailment and $\mathrm{Thr}_{\text {sur }}$ are identical with STD; $\mathrm{Thr}_{\text {def }}$ is increased to +75MW in order to obtain a similar difference between $\mathrm{Thr}_{\text {def }}$ and the maximum deficit (92 MW) as in the STD run.

\subsection{Definition of balancing potentials}

The following sections define the balancing potential of a technology or a set of several technologies. We discuss the following quantities in the text:

Actual balancing potential (surplus/deficit): The actual balancing potential takes into account balancing limitations due to limited storage capacity and plant operation schedules. The actual balancing is calculated as the difference of the residual load between the INFLEX case and the respective simulation with flexible operation (e.g. STD, STOR_12h, AltRL ...). Two cases have to be distinguished:

- The actual deficit balancing potential is the average reduction of the FFM plant's net power demand during all deficit situations (residual load $>\mathrm{Thr}_{\mathrm{def}}$ ) within the simulation year.

- The actual surplus balancing potential is the average increase of the FFM plant's net power demand all surplus situations (residual load $<\mathrm{Thr}_{\text {sur }}$ ).

Technical balancing potential: The technical balancing potential is the balancing potential without storage limitations. However, it accounts for limits due to the operation of the plant, 
as explained below. Again, different technical balancing potentials for surplus and deficit situations have to be distinguished here, as well as balancing potentials for consumers and for generation units.

- Surplus situations: The technical balancing potential for all flexible consumers is the difference between installed capacity and load during surplus situations in the INFLEX case. During a surplus situation, the load can be increased by this amount in a STD run compared to the INFLEX case. For all flexible power generation units, the technical potential is the actual capacity during surplus situations in the INFLEX case, which can be shut down in a STD run.

- Deficit situations: For all flexible consumers, the technical balancing potential is the load during deficit situations in the INFLEX case which can be shut off in the STD runs. For the CHP generation unit, the technical balancing potential is the difference between the capacity during deficit situations in the INFLEX case and the installed capacity of the CHP unit.

Theoretical balancing potential: The theoretical balancing potential is defined as the installed electric capacities of the flexible consumers and the CHP plant. It does not take into account any limitations of the flexibility potential due to plant operation or limited storage capacity.

Unused technical potential: The unused technical potential is the difference between the technical and the actual balancing potential. It is thus the technical potential which cannot be retrieved due to limited storage capacity.

\section{Results}

In the following section we first give insight into the balancing potential for each application plant and discuss how the production processes limit load balancing. Then we present sensitivity tests for a variation in storage capacity and residual load. We close with a discussion of the simulation approach and results.

\subsection{Basic simulations}

Figure 3 shows the actual balancing potential for the flexible technologies heat pump (HP), cold storage warehouse (CSW), deep freezer (DF), electric heater (EH), and the cogeneration unit (CHP) as well as the combined effect in the STD simulation (SUM): In surplus situations, nearly $50 \%$ of the theoretical balancing potential can be tapped on average; during deficit situations, this value is $40 \%$ (SUM bar in Figure 3).

The average contribution of each technology to surplus or deficit balancing varies. As described above, the potential depends strongly on the average operating status during deficit/surplus situations in the INFLEX runs. This particularly evident in the case of the CHP unit: In deficit situations, the CHP unit does not at all contribute to the residual load balancing. Two factors are mainly responsible for this fact: First, in the INFLEX run, the CHP unit is almost continuously running on nominal load (except for Sundays and holidays), providing base load process heat. Consequently, CHP power production in the STD run cannot be increased compared to the INFLEX run for most of the time. And second, on Sundays and holidays, production processes at the FFM plant are shut down. Only at these times the CHP unit could contribute to balance deficits in the STD. However, the limited high temperature storage capacity and the lack of a heat demand during weekends and holidays limit the CHP unit's deficit balancing potential also during Sundays and holidays.

In contrast, the electric heater can significantly reduce deficits - on average with $45 \%$ of its installed capacity. Also the average deficit balancing potentials of the heat pump and the two 
chillers (cold storage warehouse, deep freezing) are to a large extent explained by their low average loads in the INFLEX run, which can be shut off in the STD run in the case of a deficit. This implies that the storage capacity (6h) does not significantly limit deficit balancing in the STD run setup.

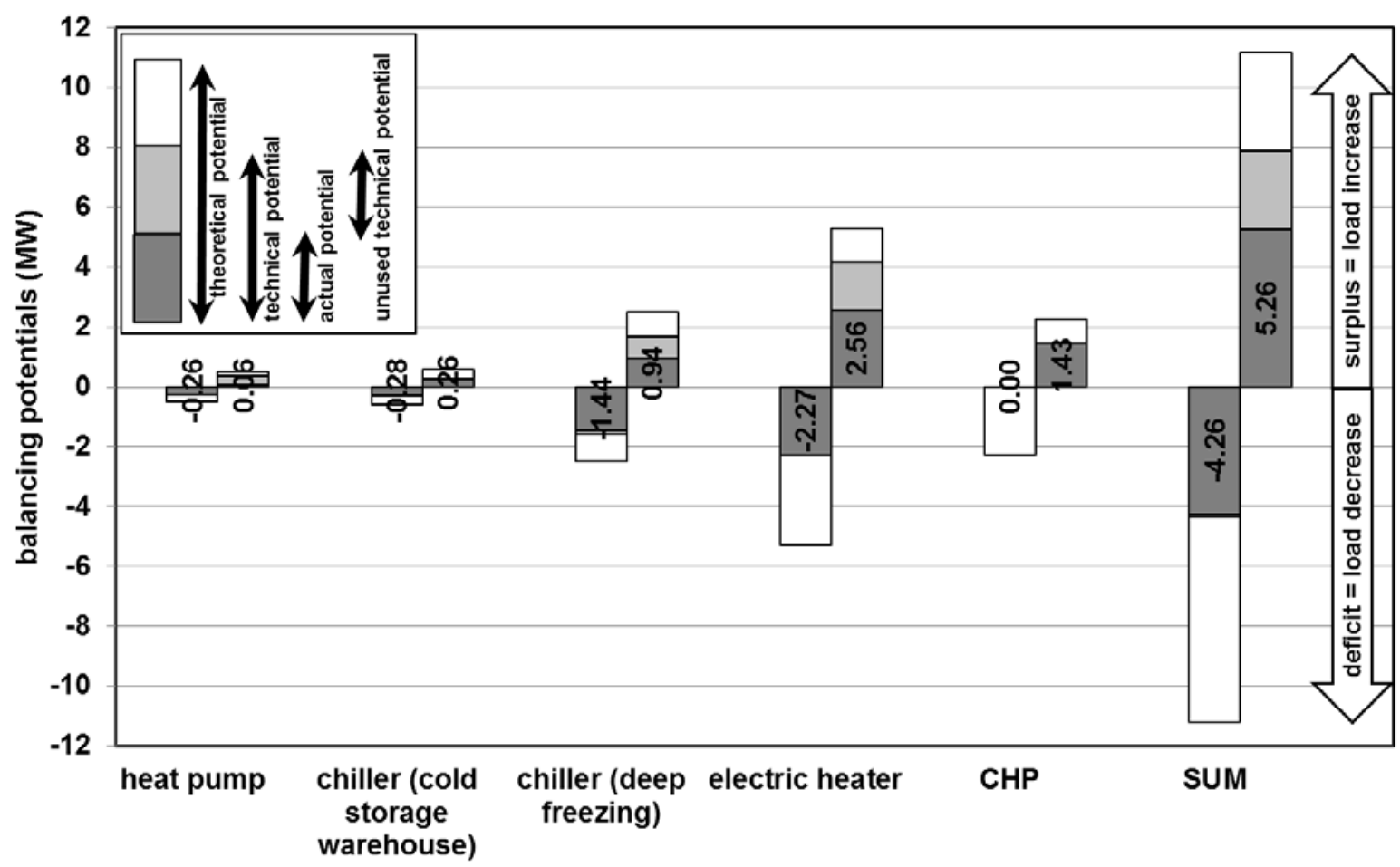

Figure 3: Balancing potentials (actual, technical, theoretical) in the STD run (compared to INFLEX), shown separately each technology and the combined effect (SUM) during strong deficit (negative values) and strong surplus situations (positive values). SUM represents the total potential of the STD run as also shown in Figure 5.

In surplus situations, the actual balancing potential of these technologies is generally higher than in the deficit situations (see Figure 3). This is again mainly explained by the fact that on average, the heat pump, the chillers, and the electric heater are operating with less than $50 \%$ of their nominal load in the INFLEX run. Their potential to increase their load in STD during surplus situations is thus higher than their potential to decrease their load during deficits.

At 1.43 MW, the actual surplus balancing potential of the CHP unit is limited. This value corresponds to the average load of the CHP unit during surplus situations in INFLEX. Thus, storage capacity does not limit the CHP's average surplus balancing potential.

However, the relatively high values for the unused technical potential during surplus situations (see Figure 3) for the chiller (deep freezing), the electric heater and the CHP indicate that in these cases the storage capacities restrict the balancing potential of the FFM plant. We thus analyse the effect of storage capacity on the balancing potential in the sensitivity test in section 3.2.

Figure 3 shows only the average balancing potential during surplus and deficit situations during the simulation year. In contrast, Figure 4 shows the hourly balancing potential during all deficit situations (upper panel) and all surplus situations (lower panel). For deficits, the combined effect of all technologies allow hourly balancing between $0.45 \mathrm{MW}$ and 6.28 MW; during surplus situations the hourly balancing ranges from 0.23 MW to 9.63 MW. The theoretical balancing potential for both surplus and deficit situations is $11.2 \mathrm{MW}$ in the 
STD simulation. The broad range in both hourly surplus and deficit balancing can be explained by broad range of hourly operating states of each technology during the course of the year in the INFLEX case, which is the base on which the hourly balancing potential in the STD simulation has to be evaluated. The low hourly surplus balancing potential at the end of the year (during the Christmas holidays) is explained below in Section 3.2.
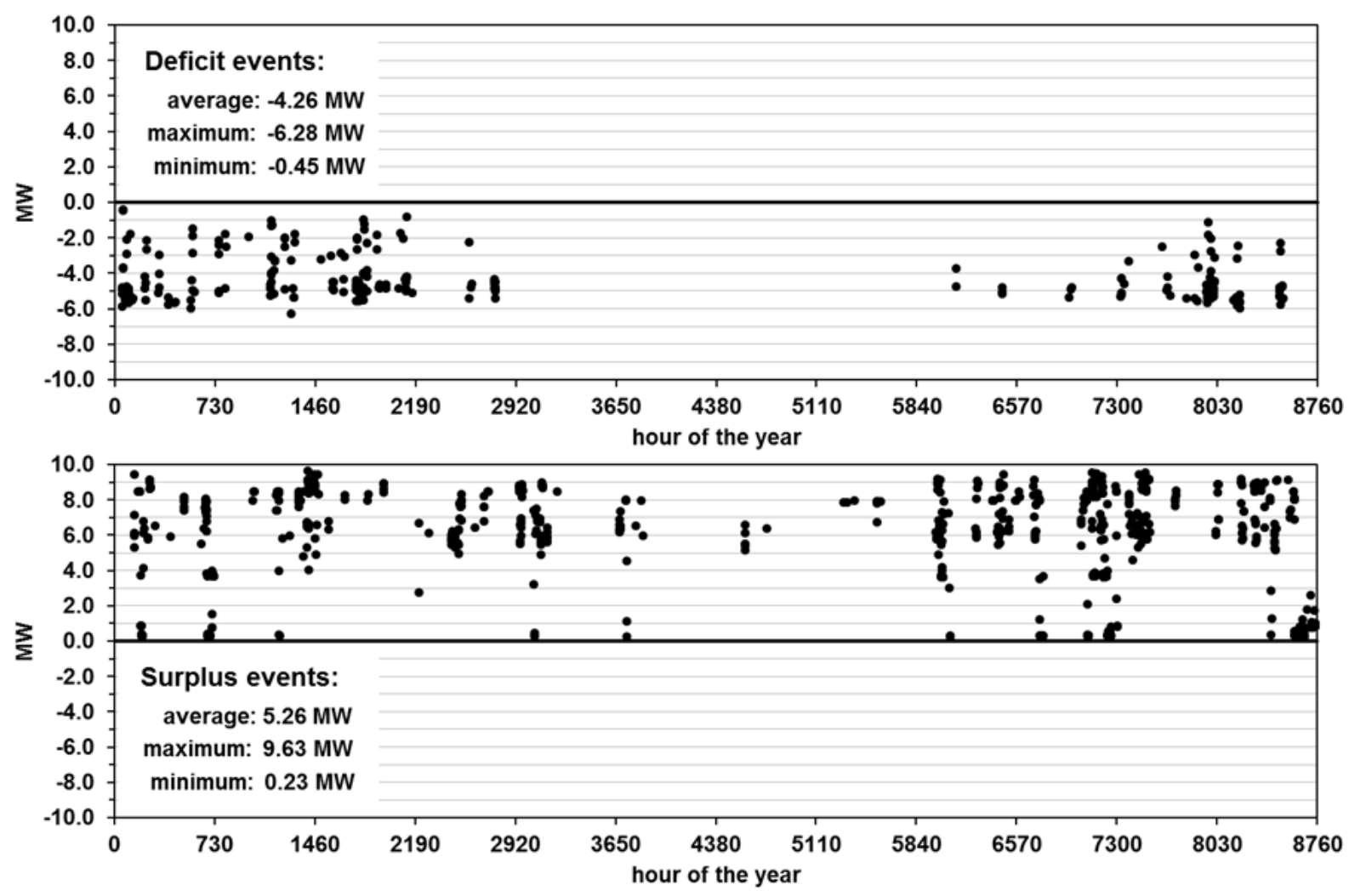

Figure 4: Change in net power demand due to DSM measures for all deficit situations (top panel) and surplus situations (bottom panel) in the STD simulations. The major ticks on the $x$ axis approximately represent one month.

\subsection{Sensitivity tests: storage capacity}

Figure 5 shows results from sensitivity tests with respect to storage capacity in the runs STOR_1h - STOR_192h. In the case of strong deficit situations, the actual balancing potential increases from $2.37 \mathrm{MW}$ at a storage capacity of $1 \mathrm{~h}$ to $4.26 \mathrm{MW}$ at $6 \mathrm{~h}$ storage capacity. Higher storage capacities only slightly increase the actual balancing (net load reduction) potential. This behaviour can be explained by the frequency distribution of strong deficit situations as shown in Figure 6 (upper panel): Most deficit situations are shorter than $3 \mathrm{~h}$. Only two situations last longer than $6 \mathrm{~h}$, the longest lasts $8 \mathrm{~h}$. Consequently, a storage capacity of $12 \mathrm{~h}$ provides enough flexibility during the entire deficit situation.

A similar reasoning holds true for the sensitivity of the actual balancing potential during surplus situations: Although more than $80 \%$ of the surplus situations are shorter than 6 hours, three surplus situations can be found in the 24-48h segment (Figure 5, lower panel). Consequently, increasing storage capacity up to $48 \mathrm{~h}$ increases the actual balancing potential. However, this argument is not sufficient to explain the further increase of the actual balancing potential with a storage capacity of more than 48h (Figure 5, runs STOR_96h and STOR_192h). A detailed analysis of these runs shows that the additional surplus balancing in STOR _192h occurs during the Christmas holidays, when food production at the FFM plant is 
shut off. As a consequence, there is no process heat demand to discharge the HT-TES. The same is true for the C-TES. In the STOR _48h run, both the HT-TES and the C-TES remain fully charged after a surplus period of two days on December $23^{\text {rd }}-25^{\text {th }}$. When the next surplus period occurs (December $26^{\text {th }}$ ), the storages are still fully charged. As a consequence, the surplus balancing potential during the December $26^{\text {th }}$ surplus situation is zero. Due to the larger storage capacity in the STOR_96h and STOR_192h runs, also surplus power from the second surplus period can be stored in both the HT-TES and the C-TES. However, it should be clear that in a real system the storages will not be dimensioned in order to be able to cover those particular situations. Furthermore, due to space limitations at the plant site, it cannot be expected that storages with capacities of $12 \mathrm{~h}$ and more will be installed in a future plant.

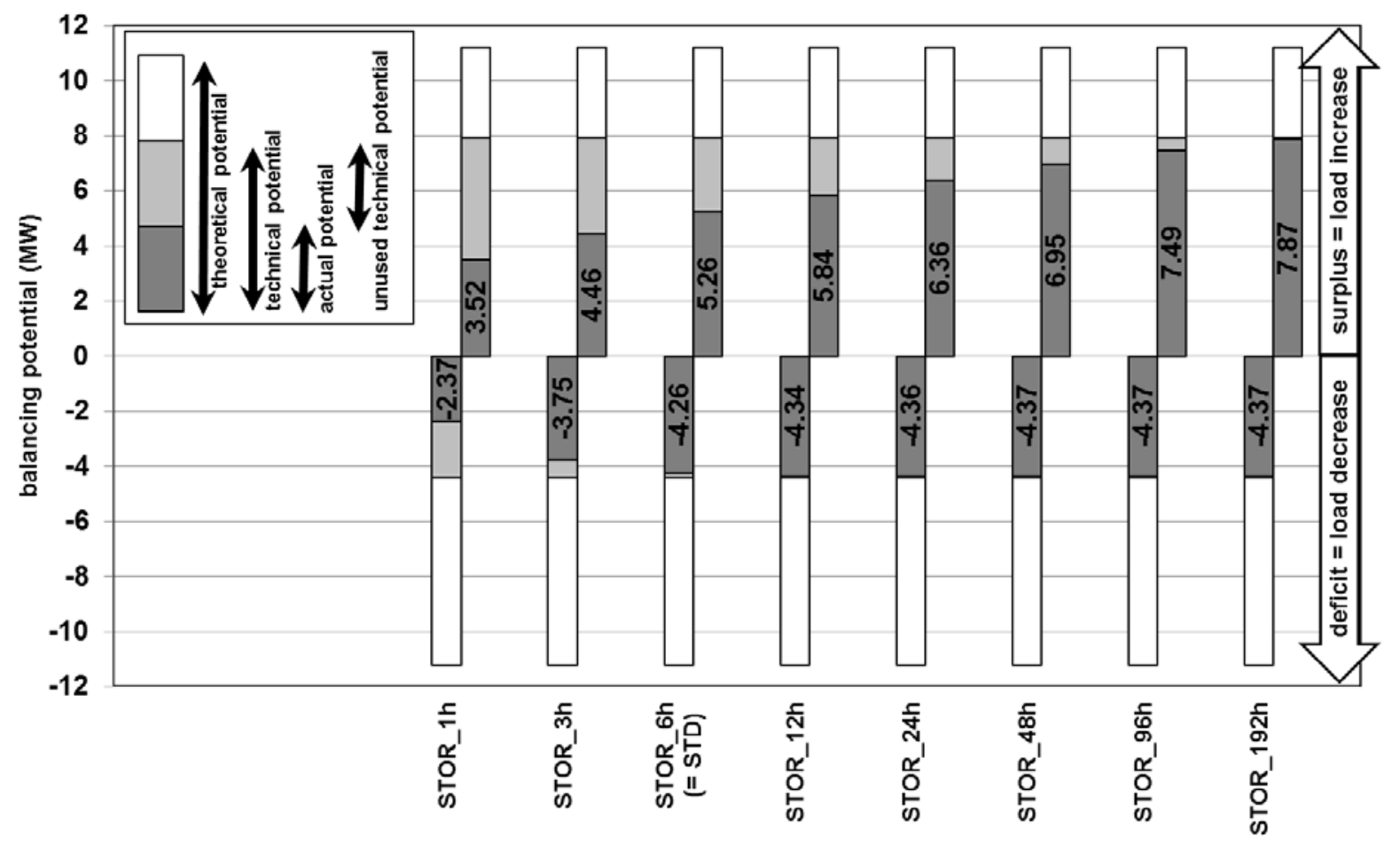

Figure 5: Results for the storage capacity sensitivity tests (STOR_1h - STOR_192h. STOR_6h is identical with STD in Figure 3

Larger storage capacities result in increased charging and discharging frequency and increased average absolute storage filling levels. As a consequence, storage losses increase with increasing storage capacity: Due to storage losses, power demand of the deep freezer chiller in STOR_6h is 3\% higher than in INFLEX and 9\% in STOR_192h. Losses of the HTTES account for $1.3 \%$ of the total process heat demand at a storage capacity of $6 \mathrm{~h}$ and for 7.5 $\%$ at a storage capacity of $192 \mathrm{~h}$. These effects are significant for a further economic analysis of the FFM plant's balancing potential.

\subsection{Sensitivity test: structure of the residual load}

The STD and the AltRL setup only differ with respect to the residual load. In the AltRL simulations, the unused potential during surplus situations is $15 \%$ lower than in the STD simulations (not shown). This is due to the fact that in AltRL surplus situations $\geq 6 \mathrm{~h}$ occur less often than in the STD residual load (Figure 6, bottom panel). Furthermore, surplus situations $\geq 6 \mathrm{~h}$ are on average shorter in AltRL compared with STD. As a consequence, in AltRL, both the HT-TES and the C-TES are less often entirely filled (and if so, for shorter periods). Thus, limited storage capacities constrain the surplus balancing potential less in AltRL than in STD. 
In contrast, during deficit periods, the unused potential for both STD and AltRL is small (not shown).

The relatively large unused technical potential during surplus situations in both STD and AltRL simulations with 6h storage capacity can only partly explained by the fact that also longer surplus situations than 6h appear (Figure 6). However, although the longest surplus periods do no exceed $48 \mathrm{~h}$ in the standard residual load (STD), Figure 5 shows that even for storage capacities of $48 \mathrm{~h}$ approximately $13 \%$ of the technical balancing potential cannot be exploited by the dispatch algorithm. This is at least partly explained by the fact that several longer surplus situations occur almost immediately after each other around Christmas. This is the case e.g. for 71 hours between time steps 7188 and 7259 (of which 67 hours belong to surplus situations) and for 79 hours between time steps 8591 and 8670 (of which 68 hours belong to surplus situations). With a storage capacity of $6 \mathrm{~h}$, the actual balancing potential is close to zero for nearly 60 hours during each of these long situations. In such cases, the time between these surplus situations is too short to allow emptying of the TESs in order to obtain the full balancing potential for the next surplus situation.
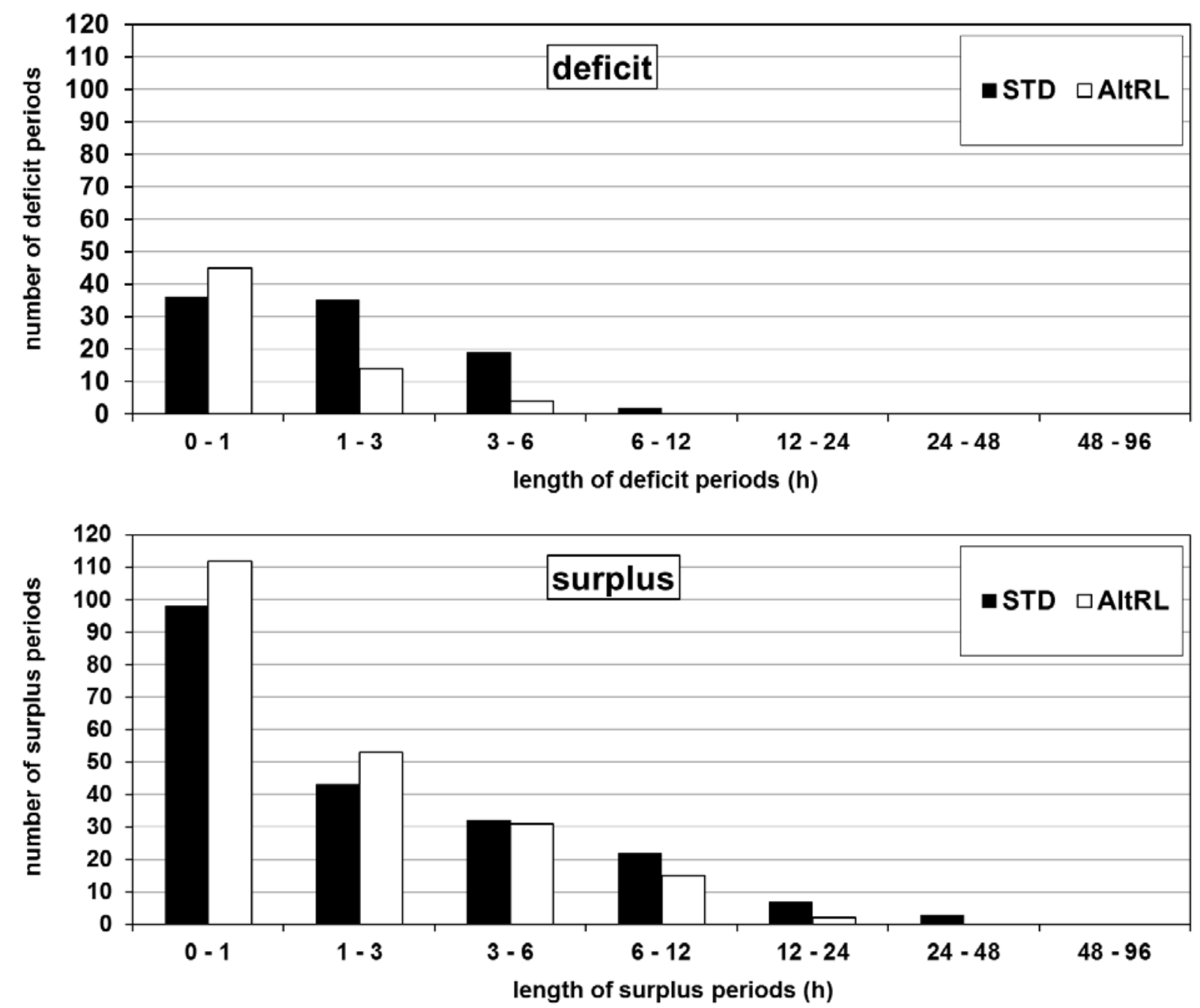

Figure 6: Frequency of strong deficit (top) and strong surplus (bottom) situations of different length; residual load for the STD and AltRL runs.

The choice of the thresholds which define "strong surplus" situations ( $\mathrm{Thr}_{\text {sur }}$ ) and "strong deficit" situations ( $\mathrm{Thr}_{\mathrm{def}}$, Section 2.4) impacts the length and the frequency of those surplus and deficit situations. Lower thresholds (in absolute values) result in more and longer deficit 
and surplus situations. As a consequence, the actual balancing potential during deficit and surplus situations decreases if the storage capacity is kept constant (results not shown).

\section{Discussion}

The analysis here is based on a newly developed heuristic dispatch algorithm (section 2.3). If adequate storage capacities are chosen, this simple algorithm is capable of exploiting a large part of the technical balancing potential of the FFM plant without applying any optimization, in particular for deficit situations. However, it could be shown that the unused technical potential depends mainly on storage capacity (measured in hours of full load) compared with the typical length of surplus or deficit periods. Thus, any algorithm aiming at maximising the actual balancing potential will have to face the same principle challenge of a limited storage capacity. Thus, although an optimisation algorithm can be expected to exploit a somewhat higher share of the technical balancing potential, it can be assumed that this additional potential is small.

There are other drawbacks of the algorithm applied here: The dispatch algorithm does not take into account the length of the surplus or deficit period when emptying (resp. filling) the TESs before the situation in order to allow maximum balancing during the situation. The algorithm thus implicitly assumes (in the STD simulations with storage capacity of 6h) that the surplus resp. deficit situation has a length of $6 \mathrm{~h}$ and thus the TESs should be totally emptied (for filled). This operation leads to an excessive use of the TESs, resulting in unnecessary losses in particular during storage charging and discharging. Thus, a more advanced dispatch algorithm could help to reduce storage losses and the final energy demand of the plant. However, as storage losses are small (on the order of a few percent of total final energy demand), the overall efficiency improvements due to an improved charging/discharging strategy are expected to be small as well.

The objective of this exemplary modelling exercise presented here was the determination of technical residual load balancing potentials of the FFM plant within a municipal energy system. Economic aspects - additional investment in storages and storage control, additional O\&M costs, costs due to higher final energy consumption due to non-negligible storage losses etc. - have not been taken into account. Furthermore, it was beyond the scope of this study to identify potential (economic) incentives for the flexibilisation of heat and cold production at FFM plant.

However, a first, rough estimate of some economic aspects can be made by a comparison of the full load hours of the technologies in the INFLEX and the STD runs: The flexible process heat generation reduces the full load hours of the CHP by more than 40\% (INFLEX: $6346 \mathrm{~h} / \mathrm{a}$, STD: $3570 \mathrm{~h} / \mathrm{a}$ ), but increases the full load hours for the electric heater by nearly $30 \%$ (INFLEX: 2185 h/a, STD: 2816 h/a, Figure A 6 and Figure A 7 in the Supplementary Material). The reduced load factor and thus reduced economic efficiency of the capital intensive CHP cannot be compensated by the increased load factor of the less capital intensive electric heater. Furthermore, full load hours of the C-TES (476 h/a for charging, 359 h/a for discharging) and the HT-TES (422 h/a and $370 \mathrm{~h} / \mathrm{a}$, respectively) are rather low in the STD simulations. The low load factors of the both the HT-TES and the C-TES suggest that additional costs for flexibility provided by the TESs will be relatively high. These results show the importance of a thorough consideration of economic aspects which are the necessary next steps to further develop both the model and the analytical approach in the future.

Bearing these potential challenges for an economic realization of the frozen food manufacturing plant's balancing potentials in mind, our study provides a first outlook on potential system service the FFM plant could provide to the municipal power system and the 
technical limitations that municipalities face while unlocking the local DSM potential. A further economic assessment of costs of system service and potential profits from the plant's participation in a local or national balancing market is needed to assess the economic potential on community level. .

Although the model was developed to analyse the balancing potential of a frozen food manufacturing plant, the general results presented can be expected to be transferable to other industry branches as well. Moreover, the model is flexible enough to simulate a wide variety of plants with similar technical components as the FFM plant considered here in this paper. As an example, within the KomRev project, an only slightly adapted version of the model has been used to estimate residual load balancing potentials of two hospitals as well. Our model therefore represents a generic tool to assess specific load balancing potential on plant level.

As stated above, the model assumes a perfect foresight of the residual load of $12 \mathrm{~h}$. Although a perfect foresight is not realistic, forecast quality for both wind and PV power generation and the electricity load are improving steadily and forecast errors are relatively low at a time horizon of $12 \mathrm{~h}$. Thus we assume that the balancing potential would not decrease significantly when assuming forecast errors. However, a practical implementation of load balancing in a plant will probably rely on more elaborated (optimising) algorithms which can be expected to perform somewhat better than the algorithm presented here even under uncertainty.

\section{Summary and conclusions}

In this paper, we simulate the potential of a frozen food manufacturing plant to balance the residual load in a local, renewable power supply system, i.e. to reduce both large deficits and large surpluses. The analysis presumed that production quantities and production schedules may not be affected by the flexible operation of the plant's energy supply system. Main findings of this study can be summarised as follows:

The analysis shows that already our simple dispatch algorithm developed for this study is capable of exploiting roughly $2 / 3$ to $3 / 4$ of the technical balancing potential of the frozen food manufacturing plant, if adequate storage capacities are chosen. It can thus be expected that more complex algorithms (e.g. optimisation algorithms) could only slightly increase the balancing potential of the plant.

The average residual load balancing potential depends on the nominal electric power of the flexible consumers (chillers, electric heater, and electric heat pump) and flexible generation units (CHP). However, this theoretical balancing potential cannot entirely be exploited. This is mainly due to two facts:

If operated flexibly, the plant's potential to change power consumption and/or production depends always on its operational state in the inflexible case. For example, a consumer operating most of the time on nominal load in the inflexible case cannot increase its load significantly in a surplus situation if operated flexibly. In contrast, its potential load decrease in a deficit situation is large. Thus, the plant's technical balancing potential during surplus and deficit situations depends strongly on the average dispatch of the flexible consumers and generation units in the inflexible reference case during these situations.

Finally, the balancing potential depends significantly on the capacities of the TESs. Not surprisingly, larger storage capacities tend to increase the balancing potential. However, the capacity necessary to exploit most of the remaining balancing potential depends on the typical length of surplus and deficit situations which are to be balanced by the flexible operation of the plant. Thus, if the storage capacity is higher than the length of most surplus and deficit periods, the actual balancing potential is close to the technical potential. Therefore a specific 
approach on plant level such as our model is necessary for a reliable assessment of municipal balancing options.

\section{Acknowledgements}

This paper is based on a project funded by the German Ministry for the Environment, Nature Conservation, Building and Nuclear Safety (BMUB) within the framework of the National Climate Protection Initiative (funding number 03KSE043B). The authors wish to thank C. Husenbeth (DLR) for data acquisition. The KomRev project partners helped with many fruitful discussions as well with sharing their simulation results: B. Fricke, A. Anthrakidis, S. Steininger, M. Schöttler (SIJ at the FH Aachen), F. Merten, C. Krüger (Wuppertal Institute for Climate, Environment, Energy), M. Wolters, G. Wermers (Leitstelle Klimaschutz Rheine). Many thanks also to R. Hennig (Apetito) for valuable insights into a frozen food plant's utility engineering and to H. C. Gils and M. Klein (DLR) for an internal review of the paper.

\section{References}

[1] UNFCCC, "Report of the Conference of the Parties on its twenty-first session, held in Paris from 30 November to 13 December 2015 - Part two: Action taken by the Conference of the Parties at its twenty-first session,” United Nations, Framework Convention on Climate Change, 2015.

[2] IRENA, “Roadmap for a renewable energy future,” International Renewable Energy Agency, 2016.

[3] REN21, "Renewables 2016 Global Status Report,” REN21 Secretariat (Renewable Energy Policy Network for the 21st Century), 2016.

[4] S. Teske, T. Pregger, S. Simon, T. Naegler, W. Graus, and C. Lins, "Energy [R]evolution 2010 - a sustainable world energy outlook,” Energy Efficiency, vol. 4, no. 3, pp. 409-433, 2011.

[5] T. Pregger, J. Nitsch, and T. Naegler, "Long-term scenarios and strategies for the deployment of renewable energies in Germany,” Energy Policy, vol. 59, pp. 350-360, 2013.

[6] IEA, “World Energy Outlook 2014,” OECD Publishing, 2014.

[7] B. Droste-Franke, B. P. Paal, C. Rehtanz, D. U. Sauer, J.-P. Schneider, M. Schreurs, and T. Ziesemer, Balancing Renewable Electricity: Energy Storage, Demand Side Management, and Network Extension from an Interdisciplinary Perspective (Ethics of Science and Technology Assessment). Springer, 2012.

[8] H. Kondziella and T. Bruckner, "Flexibility requirements of renewable energy based electricity systems - a review of research results and methodologies," Renewable and Sustainable Energy Reviews, vol. 53, pp. 10-22, 2016.

[9] G. Strbac, "Demand side management: Benefits and challenges," Energy Policy, vol. 36, no. 12, pp. 4419-4426, 2008.

[10] F. Steinke, P. Wolfrum, and C. Hoffmann, "Grid vs. storage in a 100\% renewable Europe,” Renewable Energy, vol. 50, pp. 826-832, 2013.

[11] T. Nuytten, B. Claessens, K. Paredis, J. V. Bael, and D. Six, "Flexibility of a combined heat and power system with thermal energy storage for district heating," Applied Energy, vol. 104, pp. 583-591, 2013.

[12] G. Pleßmann, M. Erdmann, M. Hlusiak, and C. Breyer, "Global Energy Storage Demand for a 100\% Renewable Electricity Supply,” Energy Procedia, vol. 46, no. 0, pp. 22-31, 2014.

[13] H. C. Gils, "Assessment of the theoretical demand response potential in Europe," Energy, vol. 67, no. 0, pp. 1-18, 2014. 
[14] A. S. Brouwer, M. van den Broek, W. Zappa, W. C. Turkenburg, and A. Faaij, "Leastcost options for integrating intermittent renewables in low-carbon power systems," Applied Energy, vol. 161, pp. 48-74, 2016.

[15] A. Mahmood, N. Javaid, M. A. Khan, and S. Razzaq, "An overview of load management techniques in smart grid," International Journal of Energy Research, vol. 39, no. 11, pp. 1437-1450, 2015.

[16] S. U. Agamah and L. Ekonomou, "Energy storage system scheduling for peak demand reduction using evolutionary combinatorial optimisation," Sustainable Energy Technologies and Assessments, vol. 23, pp. 73-82, 2017.

[17] A. D. Smith, P. J. Mago, and N. Fumo, "Benefits of thermal energy storage option combined with CHP system for different commercial building types," Sustainable Energy Technologies and Assessments, vol. 1, pp. 3-12, 2013.

[18] F. Adamek, T. Aundrup, W. Glaunsinger, M. Kleimaier, H. Landinger, M. Leuthold, B. Lunz, A. Moser, C. Pape, H. Pluntke, N. Rotering, D. U. Sauer, M. Sterner, and W. Wellßow, "Energiespeicher für die Energiewende: Speicherungsbedarf und Auswirkungen auf das Übertragungsnetz für Szenarien bis 2050,” VDE-ETG, Frankfurt a.M., 2012.

[19] M. Schlesinger, P. Hofer, A. Kemmler, A. Kirchner, S. Koziel, A. Ley, A. Piégsa, F. Seefeldt, S. Straßburg, K. Weinert, D. Lindenberger, A. Knaut, R. Malischek, S. Nick, T. Panke, S. Paulus, C. Tode, J. W. C. Lutz, U. Lehr, and P. Ulrich, "Entwicklung der Energiemärkte - Energiereferenzprognose,” Prognos AG \& Energiewirtschaftliches Institut (EWI) an der Universität $\mathrm{zu}$ Köln \& Gesellschaft für wirtschaftliche Strukturforschung (GWS), 2014.

[20] M. Stoetzer, I. Hauer, M. Richter, and Z. A. Styczynski, "Potential of demand side integration to maximize use of renewable energy sources in Germany," Applied Energy, vol. 146, no. 0, pp. 344-352, 2015.

[21] H. C. Gils, "Economic potential for future demand response in Germany - Modeling approach and case study,” Applied Energy, vol. 162, pp. 401-415, 2016.

[22] M. Paulus and F. Borggrefe, "The potential of demand-side management in energyintensive industries for electricity markets in Germany,” Applied Energy, vol. 88, no. 2, pp. 432-441, 2011.

[23] T. Naegler, S. Simon, M. Klein, and H. C. Gils, "Quantification of the European industrial heat demand by branch and temperature level," International Journal of Energy Research, vol. 39, pp. 2019-2030, 2015.

[24] P. Wrobel, Y. Scholz, and N. Roloff, “Analyse des lokal aufgelösten Energieausgleichsbedarfs in Deutschland," in Proceedings 12. Symposium Energieinnovation, 2012, pp. 1-10.

[25] I. Stadler, "Demand Response: nichtelektrische Speicher für Elektrizitätsversorgungssysteme mit hohem Anteil erneuerbarer Energien," dissertation.de, Berlin, 2006.

[26] I. Stadler, "Power grid balancing of energy systems with high renewable energy penetration by demand response," Utilities Policy, vol. 16, no. 2, pp. 90-98, 2008.

[27] M. Klobasa, "Analysis of demand response and wind integration in Germany's electricity market,” Renewable Power Generation, IET, vol. 4, no. 1, pp. 55-63, 2010.

[28] A. Grein and M. Pehnt, "Load management for refrigeration systems: Potentials and barriers,” Energy Policy, vol. 39, no. 9, pp. 5598-5608, 2011.

[29] A. Kirubakaran, S. Jain, and R. K. Nema, "A review on fuel cell technologies and power electronic interface,” Renewable and Sustainable Energy Reviews, vol. 13, no. 9, pp. 2430-2440, 2009.

[30] O. Z. Sharaf and M. F. Orhan, "An overview of fuel cell technology: Fundamentals and applications,” Renewable and Sustainable Energy Reviews, vol. 32, pp. 810-853, 2014. 
[31] R. Tamme, T. Bauer, J. Buschle, D. Laing, H. Müller-Steinhagen, and W.-D. Steinmann, "Latent heat storage above $120 \hat{\mathrm{A}}^{\circ} \mathrm{C}$ for applications in the industrial process heat sector and solar power generation," International Journal of Energy Research, vol. 32, no. 3, pp. 264-271, 2008.

[32] D. Laing and S. Zunft, "Using concrete and other solid storage media in thermal energy storage (TES) systems," Advances in Thermal Energy Storage Systems: Methods and Applications, p. 65, 2014.

[33] J. Heier, C. Bales, and V. Martin, "Combining thermal energy storage with buildings - a review,” Renewable and Sustainable Energy Reviews, vol. 42, pp. 1305-1325, 2015.

[34] T. Urbaneck, Kältespeicher: Grundlagen, Technik, Anwendung. Walter de Gruyter, 2012.

[35] acatech, "Energiespeicher - Technologiesteckbrief zur Analyse "Flexibilitätskonzepte für die Stromversorgung 2050,” Nationale Akademie der Wissenschaften Leopoldina, acatech - Deutsche Akademie der Technikwissenschaften, Union der deutschen Akademien der Wissenschaften, 2015.

[36] J. Luther and J. Schumacher-Gröhn, "INSEL - A Simulation System for Renewable Electrical Energy Supply Systems," in Tenth E.C. Photovoltaic Solar Energy Conference: Proceedings of the International Conference, held at Lisbon, Portugal, 8â€“12 April 1991, A. Luque, G. Sala, W. Palz, G. Dos Santos, and P. Helm, Eds. Dordrecht: Springer Netherlands, 1991, pp. 457-460.

[37] M. Moser, F. Trieb, T. Fichter, and J. Kern, "Renewable desalination: a methodology for cost comparison,” Desalination and Water Treatment, vol. 51, no. 4-6, pp. 11711189, 2013.

[38] M. Moser, F. Trieb, T. Fichter, J. Kern, and D. Hess, "A flexible techno-economic model for the assessment of desalination plants driven by renewable energies," Desalination and Water Treatment, vol. 55, no. 11, pp. 3091-3105, 2015.

[39] S.-I. Gustafsson, M. Rönnqvist, and M. Claesson, "Optimization models and solution methods for load management," International Journal of Energy Research, vol. 28, no. 4, pp. 299-317, 2004.

[40] D. Henning, "Cost minimization for a local utility through CHP, heat storage and load management," International Journal of Energy Research, vol. 22, no. 8, pp. 691-713, 1998.

[41] D. McLarty, C. C. Sabate, J. Brouwer, and F. Jabbari, "Micro-grid energy dispatch optimization and predictive control algorithms; A UC Irvine case study,” International Journal of Electrical Power \& Energy Systems, vol. 65, pp. 179-190, 2015.

[42] K. Deng, Y. sun, A. Chakraborty, Y. Lu, J. Brouwer, and P. G. Mehta, “Optimal Scheduling of Chiller Plant with Thermal Energy Storage using Mixed Integer Linear Programming," in Proceedings of the 2013 American Control Conference (ACC), 2013. 


\section{Appendix: Supplementary material}

\section{A1. Project Background}

This study is part of the project KomRev [1]. KomRev aimed at identifying and analysing options for a 100\% renewable energy system in 2050 on the community level. The analysis was carried out for an exemplary community in North-West Germany, the city of Rheine. One of the largest single energy consumers in Rheine is the FFM plant Apetito. Apetito is thus expected to have significant technical potentials for the balancing of the residual load in a future municipal energy system. Intensive interviews and data acquisition at the FFM plant allowed for detailed insights in Apetito's actual energy demand and supply structure. This information is the basis for the case study here which aims at assessing the future power balancing potential of any (virtual) FFM plant.

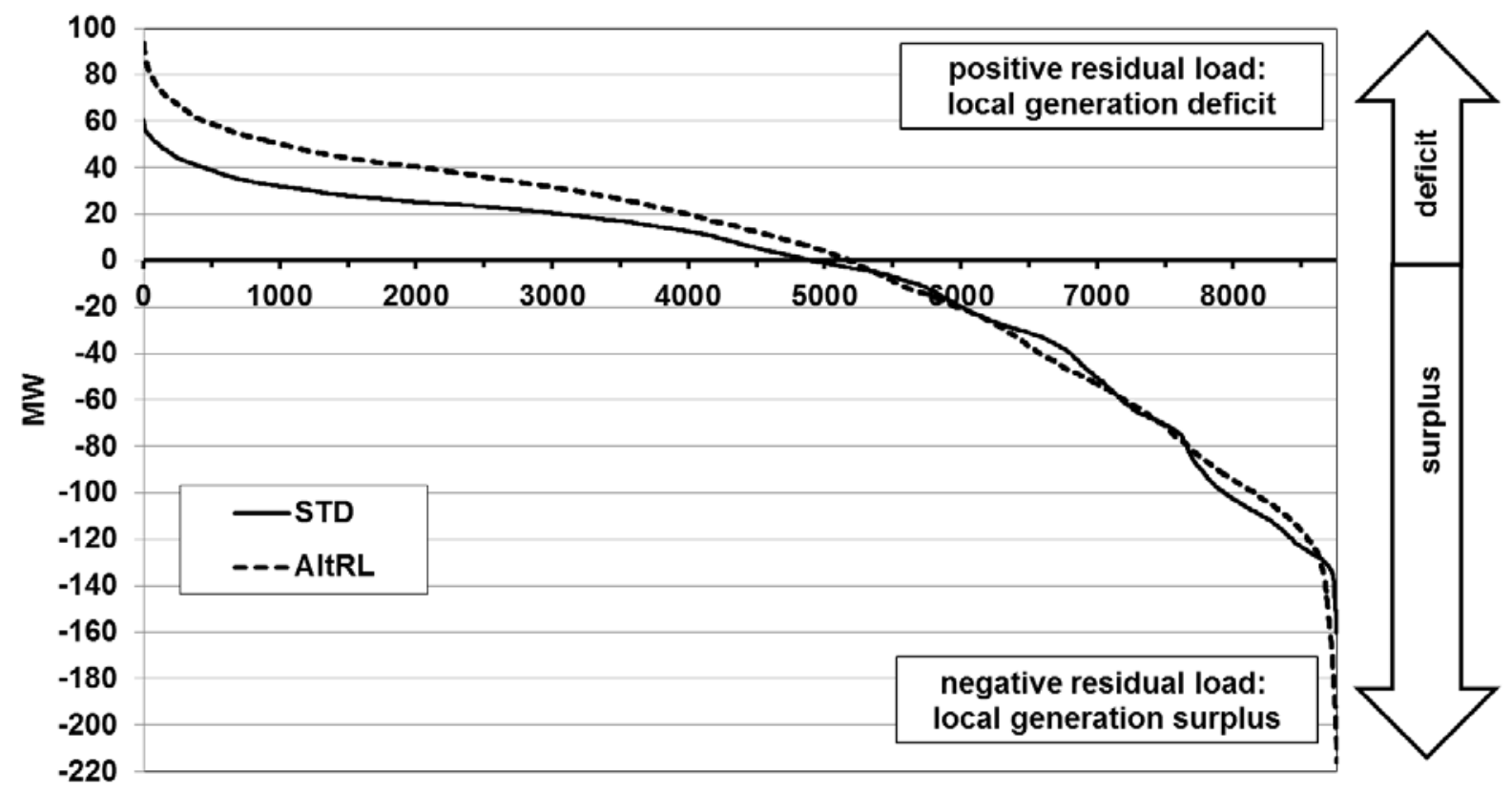

Figure A 1: Simulated sorted annual load curve of the residual load in Rheine for the two concepts STD and AltRL (see text for explanations; data courtesy of B. Fricke, Solarinstitut Jülich)

\section{A2. Residual loads for the municipal background electricity system}

The FFM plant model is imbedded in a municipal background electricity system, which is abstractly represented by the local residual load, i.e. the local non-dispatchable power production from wind and PV minus the local electricity demand (except for power demand/generation from the FFM plant). For this study, we used the residual load for Rheine for two different local $100 \%$ renewable energy supply concepts. Both concepts rely on wind power as the back bone of the electricity supply. They differ mainly in terms of low heat temperature supply and roof area usage:

- In the standard concept STD roof areas are mainly used for solar thermal systems, which feed into a district heating network with seasonal thermal energy storage.

- In the alternative concept AltRL (“Alternative Residual Load”), roof areas are mainly used for PV systems; space heat and hot water is provided by electric heat pumps. Compared with the standard concept STD, the concept AltRL results in higher 
installed capacities of PV and electric heat pumps with higher deficits and surplusses (see Figure A 1).

\section{A3. Useful energy demand and demand profiles}

Food production quantities in the model are based on data from an existing FFM plant [R. Hennig, personal communication 2014]. However, improved efficiencies of the technical equipment reduce both specific energy demand (per production unit) as well as necessary equipment capacities (thermal capacity of process heat production etc.). Estimates of technical efficiency potentials for frozen food plants were taken from C. Krüger (WI, personal communication), were technical improvements and waste heat recovery reduce the future energy demand by approximately $20 \%$ compared to today.

Table A 1 shows the annual useful energy demand and the peak load of the FFM plant's main consumer groups. Note that the useful energy demand is independent of the dispatch of the flexible heat, cold and power production technologies. It is thus identical in all simulation runs (in contrast to final energy consumption). In the case of process and climate cooling, "useful heat" denotes the extracted amount of heat (from the hot food, from the office \& production buildings and the cold storage warehouse); in the case of IIC and mechanical energy the useful energy demand is the power consumption

Table A 1: Annual useful energy demand and peak load of the FFM plant's main consumers

\begin{tabular}{|l|r|r|}
\hline \multicolumn{1}{|c|}{ consumer } & \multicolumn{1}{c|}{ peak load } & $\begin{array}{c}\text { annual useful } \\
\text { energy demand }\end{array}$ \\
\hline process heat & $4.93 \mathrm{MW}_{\text {th }}$ & $17.67 \mathrm{GWh} / \mathrm{a}$ \\
\hline process cold (deep freezing) & $4.43 \mathrm{MW}_{\text {cool }}$ & $15.61 \mathrm{GWh} / \mathrm{a}$ \\
\hline process cold (cold storage warehouse) & $1.19 \mathrm{MW}_{\text {cool }}$ & $5.89 \mathrm{GWh} / \mathrm{a}$ \\
\hline air conditioner (office and production buildings) & $1.40 \mathrm{MW}_{\text {cool }}$ & $0.54 \mathrm{GWh} / \mathrm{a}$ \\
\hline mechanical energy & $0.95 \mathrm{MW}_{\text {el }}$ & $0.35 \mathrm{GWh} / \mathrm{a}$ \\
\hline hot water & $2.81 \mathrm{MW}_{\text {th }}$ & $9.60 \mathrm{GWh} / \mathrm{a}$ \\
\hline space heat (office and production buildings) & $0.76 \mathrm{MW}_{\text {th }}$ & $2.11 \mathrm{GWh} / \mathrm{a}$ \\
\hline information, illumination, communication & $1.79 \mathrm{MW}_{\mathrm{el}}$ & $7.52 \mathrm{GWh} / \mathrm{a}$ \\
\hline
\end{tabular}

In order to represent the hourly useful energy demand for the FFM plant's production, synthetic load curves are developed for all applications where useful energy demand is not calculated endogenously in the model. These applications comprise the load curve for process heat demand, process cold demand, hot water, pressurized air and IIC. Hourly useful energy demand of these applications (except IIC) depends strongly on the plant's production schedules, which are thus crucial to analyse.

Production schedules used on the model are based on available information from an existing FFM plant [R. Henning, personal communication 2014]. Specific energy demand for the 2050 simulations has been modified as documented in Section A1 in the Supplementary Material. Load time series for the different applications were calculated from this production schedule and own assumptions on office and production hours, production quantities, set temperatures in office and production buildings as well as in the cold storage warehouse etc. 


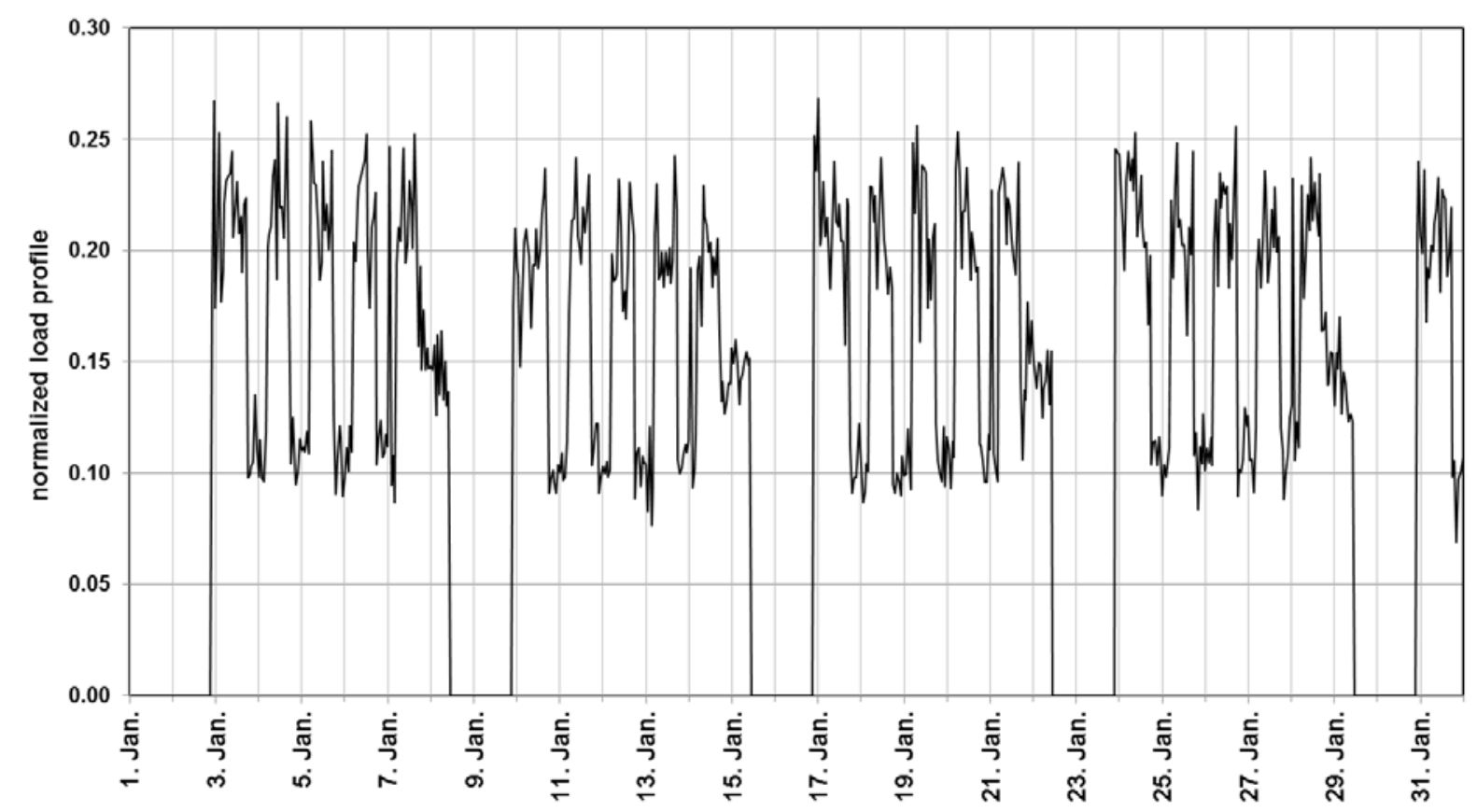

Figure A 2: normalised load curve for the process heat demand of the FFM plant

For the model, the following production schedule is assumed:

- On weekdays between 5AM and 5PM (Fridays: 4PM), all production lines are operating.

- On weekdays between 5PM and 5AM, 50\% of the production lines are operating.

- Between Friday 4PM and Saturday 10AM, the production is reduced to 70\%.

- Between Saturday 10AM and Sunday 10PM, the production is shut off entirely.

- During the summer holidays, the production is shut down for two weeks for a general overhaul and cleaning of the plant.

- $\quad$ Between December $24^{\text {th }}$ and January $2^{\text {nd }}$ production is also shut down

- Public holidays are treated as Sundays in the model.

The production schedules immediately affect the demand for process heat and indirectly the demand for hot water, process cold (deep freezing) and mechanical energy:

All production lines are regularly cleaned with hot water. Thus, the demand for hot water lags behind the process heat demand for cooking by one hour in the model. On Saturdays after the shutdown of the production all production lines are intensively cleaned. This results in an additional high hot water demand for two hours on Saturdays between 10 AM and noon.

Immediately after the cooking, the food is packed and frozen. The freezing process lasts 6090 minutes. This results in a similar time lag between process heat demand and process cooling demand. Power demand for illumination, information and communication follows the office hours; however, seasonal variations in illumination power demand are taken into account.

The "primary" load curves developed this way are unrealistically uniform from day to day. We thus added stochastic variations (normal distribution with standard deviation of $10 \%$ ) to the "primary" load curves. Figure A 2 illustrates this with a detail of the normalized load curve of the FFM's process heat demand in January.

Demand for air conditioning (heat and cold for office and production buildings) as well as the cooling demand for the cold storage warehouse were calculated from measured air 
temperature time series, assumptions on building properties (building geometry, heat transfer coefficients, thermal capacity) and set temperatures for these different buildings.

\section{A4. Basic model equations and parameters}

The following section documents the basic model equations and the parameters describing the technical performance of the CHP unit, the electric heater, the three compression chillers (deep freezing, cold storage warehouse, air conditioning), the three thermal energy storages (high temperature, low temperature and cold storage), the electric heat pump, and the compressed air unit. See Section 2.1 and Figure 1 for an overview of the model structure.

Table A 2: main model parameters for process heat technologies

\begin{tabular}{|c|c|c|c|c|c|c|c|}
\hline $\begin{array}{l}\text { process heat } \\
\text { technologies }\end{array}$ & $\stackrel{d}{ٍ}$ & 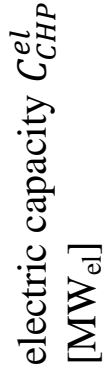 & 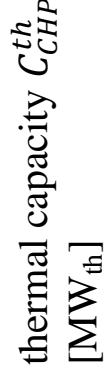 & 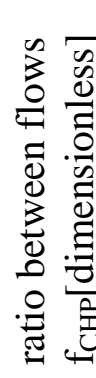 & 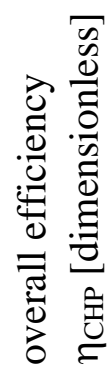 & 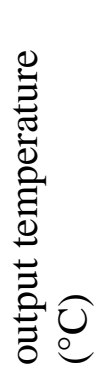 & 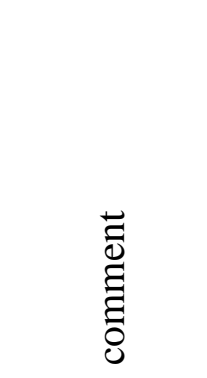 \\
\hline $\mathrm{CHP}$ & $\begin{array}{r}\text { high temperature } \\
\text { fuel cell }^{1}\end{array}$ & 2.28 & 2.05 & 1.11 & 0.73 & 400 & \multirow{2}{*}{$\begin{array}{c}\text { All runs but } \\
\text { GT, EH }\end{array}$} \\
\hline electric heater & & 4.3 & & & 0.95 & 400 & \\
\hline
\end{tabular}

The CHP unit is characterised by (see also Table A 2):

$C_{C H P}^{e l}$ : nominal electric capacity of the CHP unit $\left[\mathrm{MW}_{\mathrm{el}}\right]$

$f_{C H P}$ : ratio between flows for CHP (constant) [dimensionless]

$\eta_{C H P}$ : total efficiency CHP (with respect to lower heating value) [dimensionless]

$C_{C H P}^{e l, a}\left(t_{n}\right)$ : actual electric capacity of CHP at time step $\mathrm{t}_{\mathrm{n}}\left[\mathrm{MW}_{\mathrm{el}}\right]$

$C_{C H P}^{t h, a}\left(t_{n}\right)$ : actual thermal capacity (heat output) of the CHP at time step $\mathrm{t}_{\mathrm{n}}\left[\mathrm{MW}_{\mathrm{th}}\right]$

$G_{C H P}^{a}\left(t_{n}\right)$ : actual gas consumption of the CHP at time step $t_{n}$ (with respect to lower heating value) $\left[\mathrm{MW}_{\mathrm{lhv}}\right]$

It holds that:

$$
\begin{aligned}
& C_{C H P}^{e l, a}\left(t_{n}\right) \leq C_{C H P}^{e l} \\
& C_{C H P}^{e l, a}\left(t_{n}\right)=C_{C H P}^{t h, a}(t) \cdot f_{C H P} \\
& G_{C H P}^{a}\left(t_{n}\right)=\left(C_{C H P}^{e l, a}\left(t_{n}\right)+C_{C H P}^{t h, a}\left(t_{n}\right)\right) \cdot \eta_{C H P}
\end{aligned}
$$

The electric heater is characterised by (see also Table A 2):

\footnotetext{
${ }^{1}$ Basic fuel cell CHP parameters in the model were taken from [2]. 
$C_{E H}^{e l}$ : nominal electric capacity of the electric heater

$\eta_{E H}$ : total efficiency electric heater

$C_{E H}^{e l, a}\left(t_{n}\right)$ : actual electric capacity of the electric heater at time step $t_{\mathrm{n}}\left[\mathrm{MW}_{\mathrm{el}}\right]$

$C_{E H}^{t h, a}\left(t_{n}\right)$ : actual thermal capacity (heat output) of the electric heater at time step $t_{n}$ $\left[\mathrm{MW}_{\mathrm{th}}\right]$

It holds that:

$$
\begin{aligned}
& C_{E H}^{e l, a}\left(t_{n}\right) \leq C_{E H}^{e l} \\
& C_{E H}^{t h, a}\left(t_{n}\right)=C_{E H}^{e l, a}\left(t_{n}\right) \cdot \eta_{E H}
\end{aligned}
$$

Any of the compression chillers are characterised by (see also Table A 3):

$C_{C H}^{e l}$ : nominal electric capacity of chiller $\left[\mathrm{MW}_{\mathrm{el}}\right]$

$\eta_{C H}$ : efficiency of chiller (relative to Carnot factor) [dimensionless]

$C_{C H}^{e l, a}(t)$ : actual electric capacity of the chiller at time step $\mathrm{t}_{\mathrm{n}}\left[\mathrm{MW}_{\mathrm{el}}\right]$

$C_{C H}^{c o l d, a}(t)$ : actual cooling capacity of the chiller at time step $t_{n}\left[\mathrm{MW}_{\text {cold }}\right]$

$T_{C H}^{e v a}\left(\mathrm{t}_{\mathrm{n}}\right)$ : temperature at evaporator chiller at time step $\mathrm{t}_{\mathrm{n}}[\mathrm{K}]$

$T_{C H}^{c o n d}\left(\mathrm{t}_{\mathrm{n}}\right)$ : temperature at condenser chiller at time step $\mathrm{t}_{\mathrm{n}}[\mathrm{K}]$

$T_{C H}^{u s e}\left(\mathrm{t}_{\mathrm{n}}\right)$ : necessary temperature level for chiller applications at time step $\mathrm{t}_{\mathrm{n}}[\mathrm{K}]$

$T_{C H}^{W H, \text { cond }}(\mathrm{t})$ : temperature waste heat from condenser chiller at time step $\mathrm{t}_{\mathrm{n}}[\mathrm{K}]$

$\epsilon(\mathrm{t})$ energy efficiency ratio at time step $\mathrm{t}_{\mathrm{n}}$ [dimensionless]

$W H_{C H}\left(t_{n}\right)$ : total waste heat from chiller at time step $t_{\mathrm{n}}\left[\mathrm{MW}_{\mathrm{th}}\right]$

$W H_{C H}^{c o n d}\left(t_{n}\right)$ : waste heat from condenser at time step $\mathrm{t}_{\mathrm{n}}\left[\mathrm{MW}_{\mathrm{th}}\right]$

$W H_{C H}^{c o m p}\left(t_{n}\right)$ : waste heat from compressor at time step $\mathrm{t}_{\mathrm{n}}\left[\mathrm{MW}_{\mathrm{th}}\right]$

$W H_{C H}^{d s u p}\left(t_{n}\right)$ : waste heat from desuperheater at time step $\mathrm{t}_{\mathrm{n}}\left[\mathrm{MW}_{\mathrm{th}}\right]$

It holds that:

$$
\begin{aligned}
& C_{C H}^{e l, a}\left(t_{n}\right) \leq C_{C H}^{e l} \\
& \varepsilon\left(t_{n}\right)=\frac{C_{C H}^{c o l d, a}\left(t_{n}\right)}{C_{C H}^{e l, a}\left(t_{n}\right)}=\eta_{C H} \cdot \frac{T_{C H}^{e v a}\left(t_{n}\right)}{T_{C H}^{c o n d}\left(t_{n}\right)-T_{C H}^{e v a}\left(t_{n}\right)} \\
& T_{C H}^{e v a}\left(t_{n}\right)=T_{C H}^{u s e}\left(t_{n}\right)-5 \\
& T_{C H}^{c o n d}\left(t_{n}\right)=T_{C H}^{W H, c o n d}\left(t_{n}\right)+5 \\
& W H_{C H}\left(t_{n}\right)=W H_{C H}^{c o n d}\left(t_{n}\right)+W H_{C H}^{c o m p}\left(t_{n}\right)+W H_{C H}^{d s u p}\left(t_{n}\right)=C_{C H}^{e l, a}\left(t_{n}\right)+C_{C H}^{\text {cold,a }}\left(t_{n}\right)
\end{aligned}
$$


Table A 3: model parameters for the compression chillers

\begin{tabular}{|c|c|c|c|c|c|c|}
\hline application for chiller & 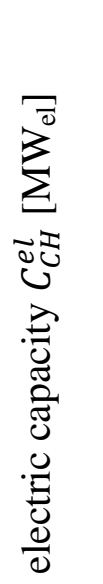 & 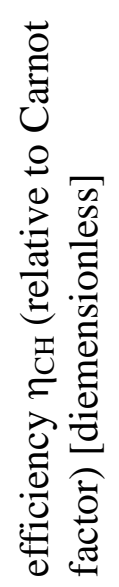 & 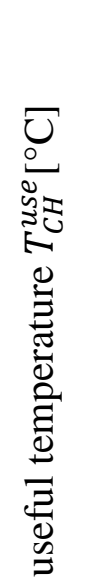 & 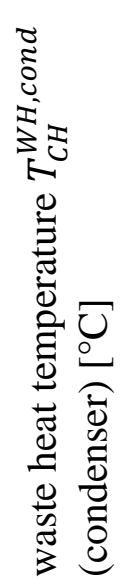 & 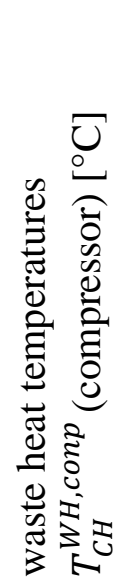 & 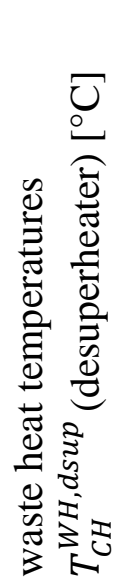 \\
\hline deep freezer & 2.5 & 0.55 & -33 & 35 & 70 & 70 \\
\hline cold storage warehouse & 0.5 & 0.5 & -25 & 35 & 70 & 70 \\
\hline air conditioning & 0.35 & 0.5 & 12 & 35 & 70 & 70 \\
\hline
\end{tabular}

Any of the thermal energy storages (TES) are characterised by (see also Table A 4):

$C_{T E S}^{\text {char }}, C_{T E S}^{\text {dis }}$ : nominal charging/discharging capacity of any TES $\left[\mathrm{MW}_{\mathrm{th}}\right]$

$S C_{T E S}^{\text {stor }}$ : storage capacity of any TES [MWh $\left.\mathrm{M}_{\mathrm{th}}\right]$

$\eta_{T E S}^{\text {char }}, \eta_{T E S}^{\text {dis }}$ : charging/discharging efficiency any TES [dimensionless]

$s d_{T E S}$ : self-discharge-rate of any TES [1/hr]

$C_{T E S}^{\text {char, } a}\left(t_{n}\right), C_{T E S}^{\text {dis, } a}\left(t_{n}\right)$ : actual charging and discharging capacity, respectively, of any TES at time step $t_{n}\left[\mathrm{MW}_{\text {th }}\right]$

$S O C_{T E S}\left(t_{n}\right)$ : actual state of charge of any TES at time step $\mathrm{t}_{\mathrm{n}}\left[\mathrm{MWh}_{\mathrm{th}}\right]$

$\Delta t=t_{n}-t_{n-1}:$ time step (1hr)

It holds that:

$$
\begin{aligned}
& \operatorname{SOC}_{T E S}\left(t_{n}\right)=S O C_{T E S}\left(t_{n-1}\right) \cdot\left(1-s d_{T E S} \cdot \Delta t\right)+C_{T E S}^{\text {char, }}\left(t_{n}\right) \cdot \eta_{T E S}^{\text {char }}-\frac{C_{T E S}^{\text {dis,a }}\left(t_{n}\right)}{\eta_{T E S}^{\text {dis }}} \\
& C_{T E S}^{\text {char,a }}(t) \leq C_{T E S}^{\text {char }} \\
& C_{T E S}^{\text {dis }, a}(t) \leq C_{T E S}^{\text {dis }} \\
& C_{T E S}^{\text {char }}=C_{T E S}^{\text {dis }} \\
& \eta_{T E S}^{\text {char }}=\eta_{T E S}^{\text {dis }}
\end{aligned}
$$

The preceding equations hold for all three TES, the HT-TES, the LT-TES and the C-TES in the same way. 
Table A 4: model parameters for the storages HT-TES, LT-TES, and C-TES

\begin{tabular}{|c|c|c|c|c|c|c|}
\hline $\begin{array}{c}\text { storage } \\
\text { technologies }\end{array}$ & $\overbrace{ٍ}^{\circledR}$ & 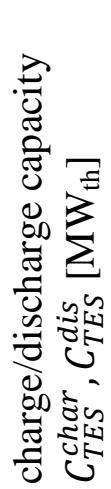 & 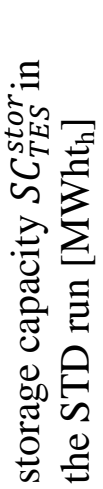 & 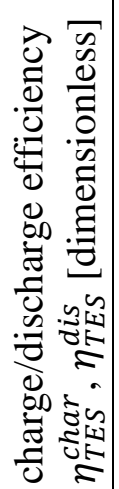 & 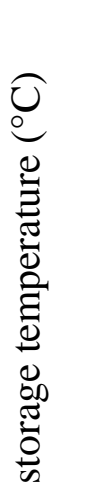 & 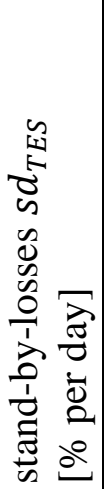 \\
\hline HT-TES & latent heat storage & 5.0 & 30 & 0.95 & 200 & 1 \\
\hline LT-TES & hot water storage tank & 3.5 & 21 & 0.95 & 70 & 5 \\
\hline C-TES & latent heat storage & 4.4 & 26.4 & 0.95 & -33 & 1 \\
\hline
\end{tabular}

The electric heat pump for waste heat upgrading is characterised by (see also Table A 5):

$C_{H P}^{e l}$ : nominal electric capacity of heat pump [MW $\left.\mathrm{MW}_{\mathrm{el}}\right]$

$\eta_{H P}$ : efficiency of heat pump (relative to Carnot factor) [dimensionless]

$\operatorname{COP}\left(t_{n}\right)$ : coefficent of performance of heat pump at time step $t_{n}$ [dimensionless]

$C_{H P}^{e l, a}\left(t_{n}\right)$ : actual electric capacity of heat pump at time step $\mathrm{t}_{\mathrm{n}}\left[\mathrm{MW}_{\mathrm{el}}\right]$

$C_{H P}^{t h, a}\left(t_{n}\right)$ : actual thermal capacity of heat pump (useful energy output) at time step $t_{n}$ $\left[\mathrm{MW}_{\mathrm{el}}\right]$

$T_{H P}^{\text {out }}$ : output temperature (useful energy) of heat pump [K]

$T_{H P}^{i n}\left(t_{n}\right)$ : input temperature (cold reservoir, i.e. waste heat ${ }^{2}$ ) of heat pump at time step $\mathrm{t}_{\mathrm{n}}[\mathrm{K}]$.

Table A 5: model parameters for the electric heat pump for waste heat upgrading

\begin{tabular}{|l|l|l|l|}
\hline & $\begin{array}{l}\text { electric capacity } \\
C_{H P}^{e l}\left[\mathrm{MW}_{\mathrm{el}}\right]\end{array}$ & $\begin{array}{l}\text { efficiency } \eta_{\mathrm{HP}} \text { (relative to } \\
\text { Carnot factor) } \\
\text { [dimensionless] }\end{array}$ & $\begin{array}{l}\text { useful temperature } \\
T_{H P}^{\text {out }\left[{ }^{\circ} \mathrm{C}\right]}\end{array}$ \\
\hline electric heat pump & 0.5 & 0.5 & 70 \\
\hline
\end{tabular}

It holds that:

$$
\begin{aligned}
& \operatorname{COP}\left(t_{n}\right)=\frac{C_{H P}^{t h, a}\left(t_{n}\right)}{C_{H P}^{e l, a}\left(t_{n}\right)}=\eta_{H P} \cdot \frac{T_{H P}^{i n}\left(\mathrm{t}_{n}\right)}{T_{H P}^{\text {out }}-T_{H P}^{\text {in }}\left(\mathrm{t}_{n}\right)} \\
& C_{H P}^{e l, a}\left(t_{n}\right) \leq C_{H P}^{e l}
\end{aligned}
$$

\footnotetext{
${ }^{2}$ In the model runs, $T_{H P}^{i n}$ is calculated as the weighted mean temperature of all waste heat flows (from the chillers and the compressed air units) 


\begin{tabular}{|c|c|c|c|c|c|}
\hline & 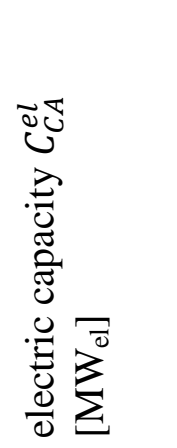 & 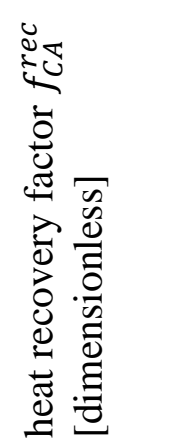 & 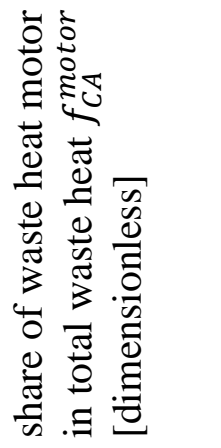 & 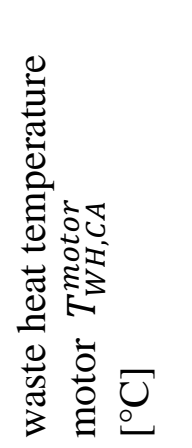 & 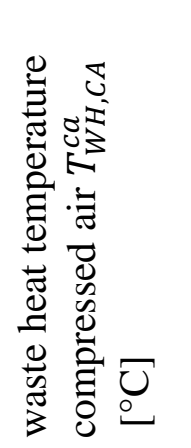 \\
\hline electric heat pump & 0.095 & 0.95 & 0.85 & 90 & 70 \\
\hline
\end{tabular}

The compressed air unit is characterised by (see also Table A 6)

$C_{C A}^{e l}$ :nominal electric capacity of compressed air unit [MW $\left.\mathrm{MW}_{\mathrm{el}}\right]$

$f_{C A}^{r e c}$ : total heat recovery factor [dimensionless]

$f_{C A}^{\text {motor }}$ : share of waste heat from motor in total waste heat [dimensionless]

$C_{C A}^{e l, a}\left(t_{n}\right)$ :actual electric capacity of compressed air unit at time step $t_{\mathrm{n}}\left[\mathrm{MW}_{\mathrm{el}}\right]$

$W H_{C A}^{\text {motor }}\left(t_{n}\right)$ : recoverable waste heat from motor cooling

$W H_{C A}^{c a}\left(t_{n}\right)$ : recoverable waste heat from compressed air cooling

It holds that:

$$
\begin{aligned}
& W H_{C A}^{\text {motor }}\left(t_{n}\right)=C_{C A}^{e l, a}\left(t_{n}\right) \cdot f_{C A}^{r e c} \cdot f_{C A}^{\text {motor }} \\
& W H_{C A}^{c a}\left(t_{n}\right)=C_{C A}^{e l, a}\left(t_{n}\right) \cdot f_{C A}^{r e c} \cdot\left(1-f_{C A}^{\text {motor }}\right) \\
& C_{C A}^{e l, a}\left(t_{n}\right) \leq C_{C A}^{e l}
\end{aligned}
$$

At each time step, the energy balances for process heat, process cold, space heat and hot water, and waste heat have to be met. This means:

$P H\left(t_{n}\right)$ : process heat demand at time step $\mathrm{t}_{\mathrm{n}}\left[\mathrm{MW}_{\mathrm{th}}\right]$

$P C\left(t_{n}\right)$ : process cold demand at time step $t_{n}\left[\mathrm{MW}_{\mathrm{th}}\right]$

$S H\left(t_{n}\right)$ : demand for space heat and hot water at time step $t_{n}\left[\mathrm{MW}_{\mathrm{th}}\right]$

$C_{W H}^{H T}\left(t_{n}\right)$ : waste heat production $>70^{\circ} \mathrm{C}$ at time step $\mathrm{t}_{\mathrm{n}}\left[\mathrm{MW}_{\mathrm{th}}\right]$

In the following equations, the subscripts HT-TES, LT-TES, and C-TES refer to the high temperature, low temperature, and cold storage, respectively.

In the following equations, the subscript $\mathrm{CH}-\mathrm{PC}$ refers to the chiller for process cold (freezer)

it holds that 


$$
\begin{aligned}
& P H\left(t_{n}\right)+C_{H T-T E S}^{\text {char, },}\left(t_{n}\right)=C_{C H P}^{t h, a}\left(t_{n}\right)+C_{E H}^{t h, a}\left(t_{n}\right)+C_{H T-T E S}^{\text {dis, } a}\left(t_{n}\right) \\
& S H\left(t_{n}\right)+C_{L T-T E S}^{\text {char,a }}\left(t_{n}\right)=C_{H P}^{t h, a}\left(t_{n}\right)+C_{L T-T E S}^{\text {dis,a }}\left(t_{n}\right)+C_{W H}^{H T}\left(t_{n}\right) \\
& P C\left(t_{n}\right)+C_{C-T E S}^{\text {char,a }}\left(t_{n}\right)=C_{C H-P C}^{t h, a}\left(t_{n}\right)+C_{C-T E S}^{\text {dis,a }}\left(t_{n}\right)
\end{aligned}
$$

\section{A5. Illustration of the hourly dispatch during flexible operation of chillers and process heat generation}

Figure A 3 - Figure A 5 illustrate the principles of the flexible operation of the chillers for deep freezing and the cold storage warehouse as well as the electric heater and the CHP unit for process heat production. All three figures show an extract of the simulation results from the INFLEX and the STD simulations for 68 hours in January. The residual load which triggers the dispatch of all flexible consumers, generation units, and storages in these figures is shown in the bottom panel of Figure A 3.

Flexible operation of the deep freezing (chiller + C-TES)

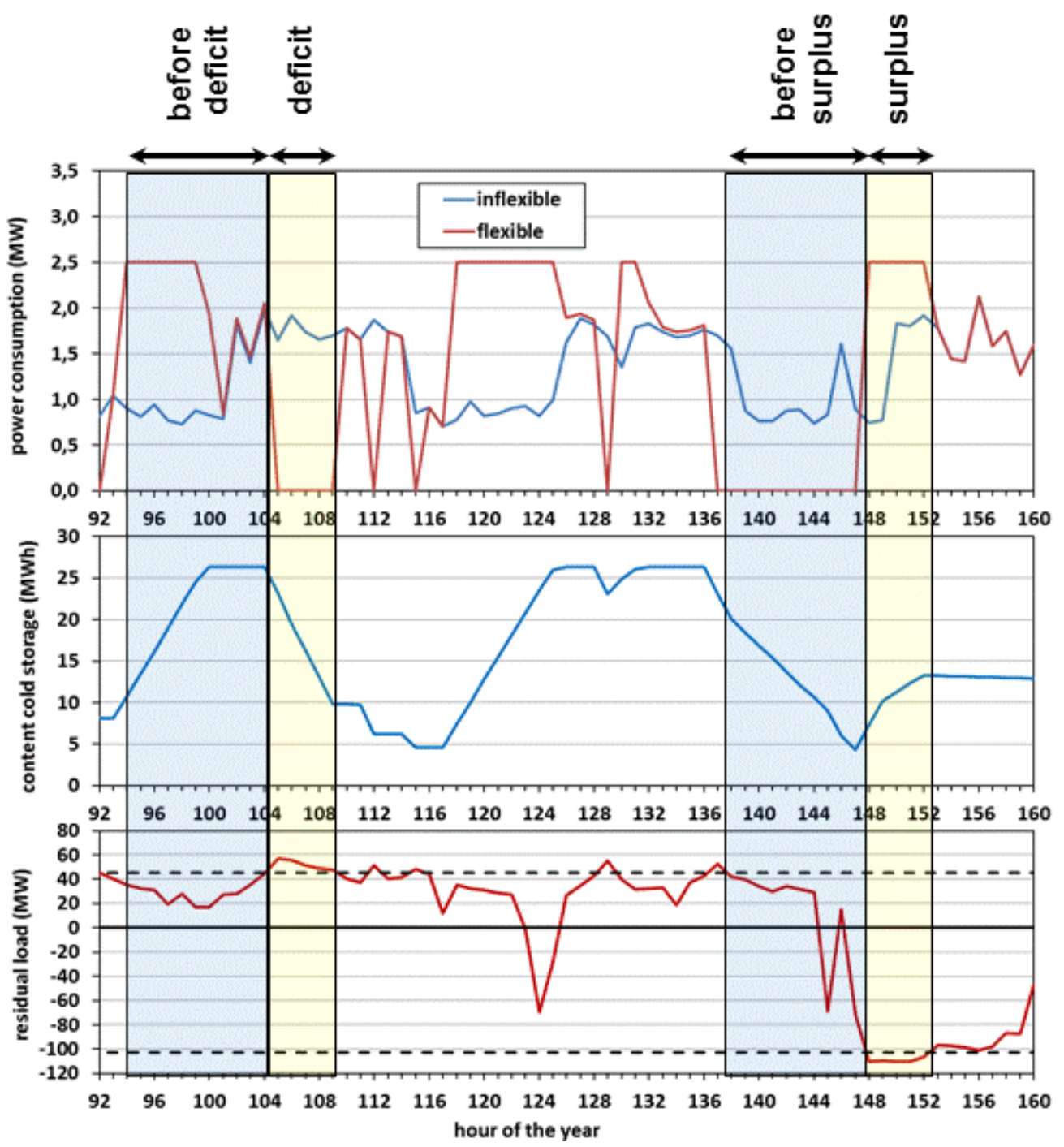

Figure A 3: Illustration of the flexible dispatch of the chiller for the deep freezer (upper panel), the filling level of the corresponding C-TES (middle panel) and the residual load (bottom panel). 
Figure A 3 illustrates the flexible operation of the chiller and the C-TES for the deep freezing:

- During intermediate situations, the chiller supplies the process cold demand; C-TES is not used

- Before a strong surplus situation, the C-TES is emptied. Thus, process cold demand is supplied by the C-TES. The chiller is shut off.

- During a strong surplus situation, the chiller runs with nominal load (regardless of process heat demand) and thus helps to reduce the local surplus power production. Surplus process cold is used to charge the C-TES, its filling level increases.

- Before a strong deficit situation, the C-TES is filled. The chiller runs on nominal load (regardless of process cold demand). Surplus cold is stored in the C-TES, its filling level increases.

- During a strong deficit situation: The chiller is shut off in order not to increase the local power generation deficit. Process cold demand is supplied by the C-TES, its filling level decreases.

Flexible operation of the chiller for the cold storage warehouse

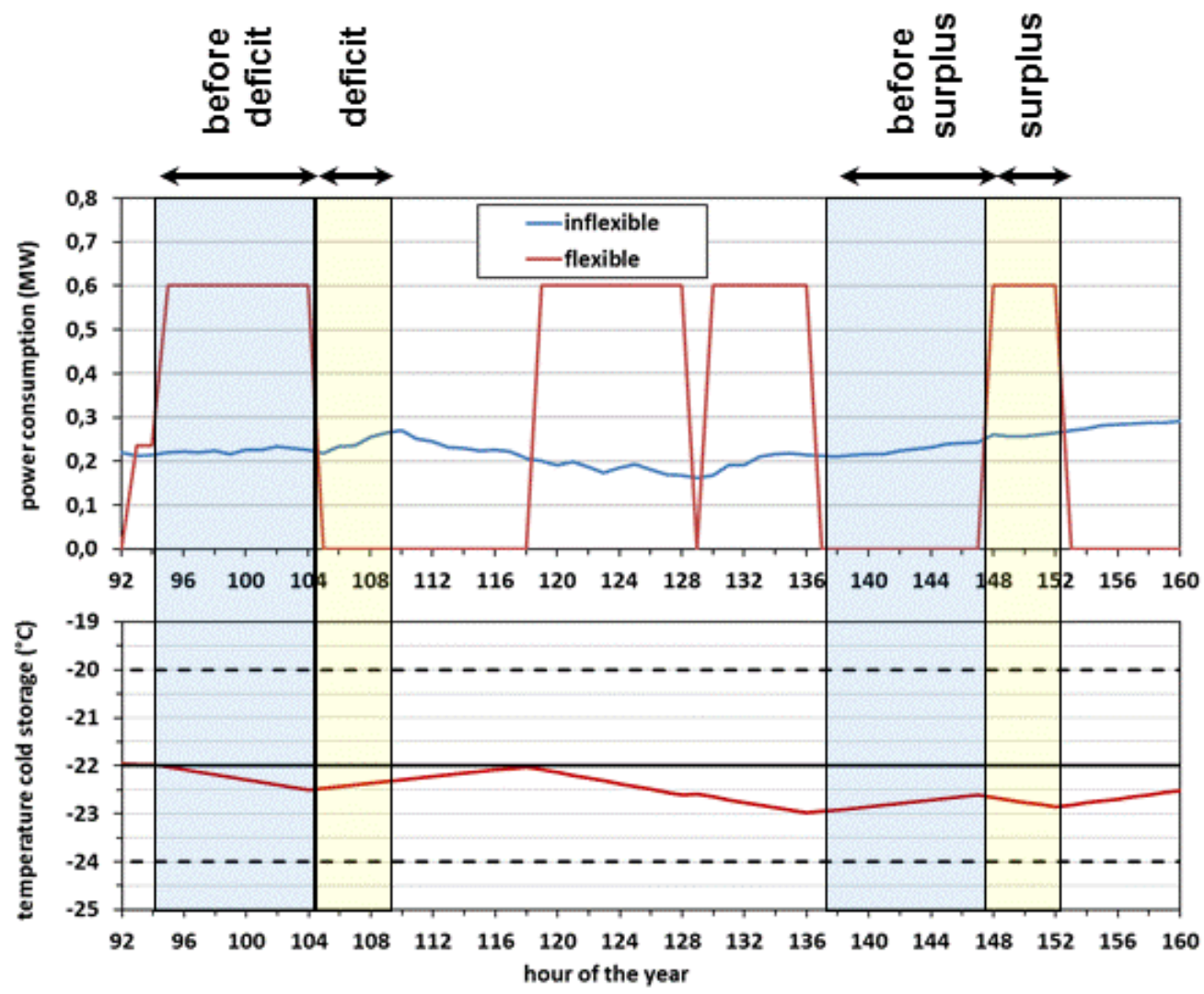

Figure A 4: Illustration of the flexible dispatch of the chiller for the cold storage warehouse (upper panel) and warehouse temperature $T_{C S W}$ (bottom panel). Black dashed line in the bottom panel: Technical upper and lower limits for $T_{C S w}$. Solid black line: set temperature.

Figure A 4 illustrates the flexible operation of the chiller for the cold storage warehouse and consequences for cold storage warehouse temperatures.

- In intermediate situations, the chiller is operated in order to keep the cold storage warehouse temperatures at the set level of $-22^{\circ} \mathrm{C}$. In the example in Figure A 4, the chiller does not operate during the intermediate situation (1), because warehouse temperatures at the beginning of the situation are below the set level. 
- Before a strong surplus situation, the chiller is shut off; cold storage warehouse temperature increases to give maximum room for a temperature decrease during the surplus situation itself.

- During the strong surplus situation, the chiller runs in nominal load, in order to reduce surplus power production. Cold storage warehouse temperatures fall again.

- Before a deficit situation, the chiller runs on nominal load; cold storage warehouse temperature decreases to give room for a temperature increase during the deficit situation.

- During the strong deficit situation, the chiller is turned off in order not to increase the deficit any more. The cold storage warehouse temperature is rising again.

Flexible operation of the electric heater, the CHP plant and the HT-TES for process heat

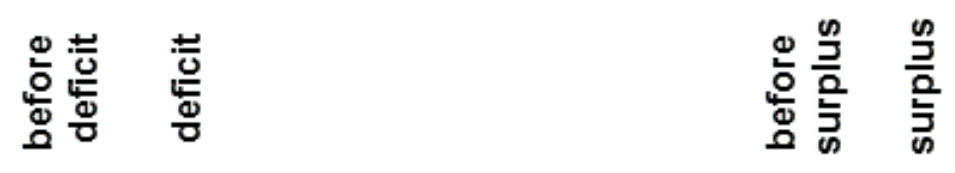
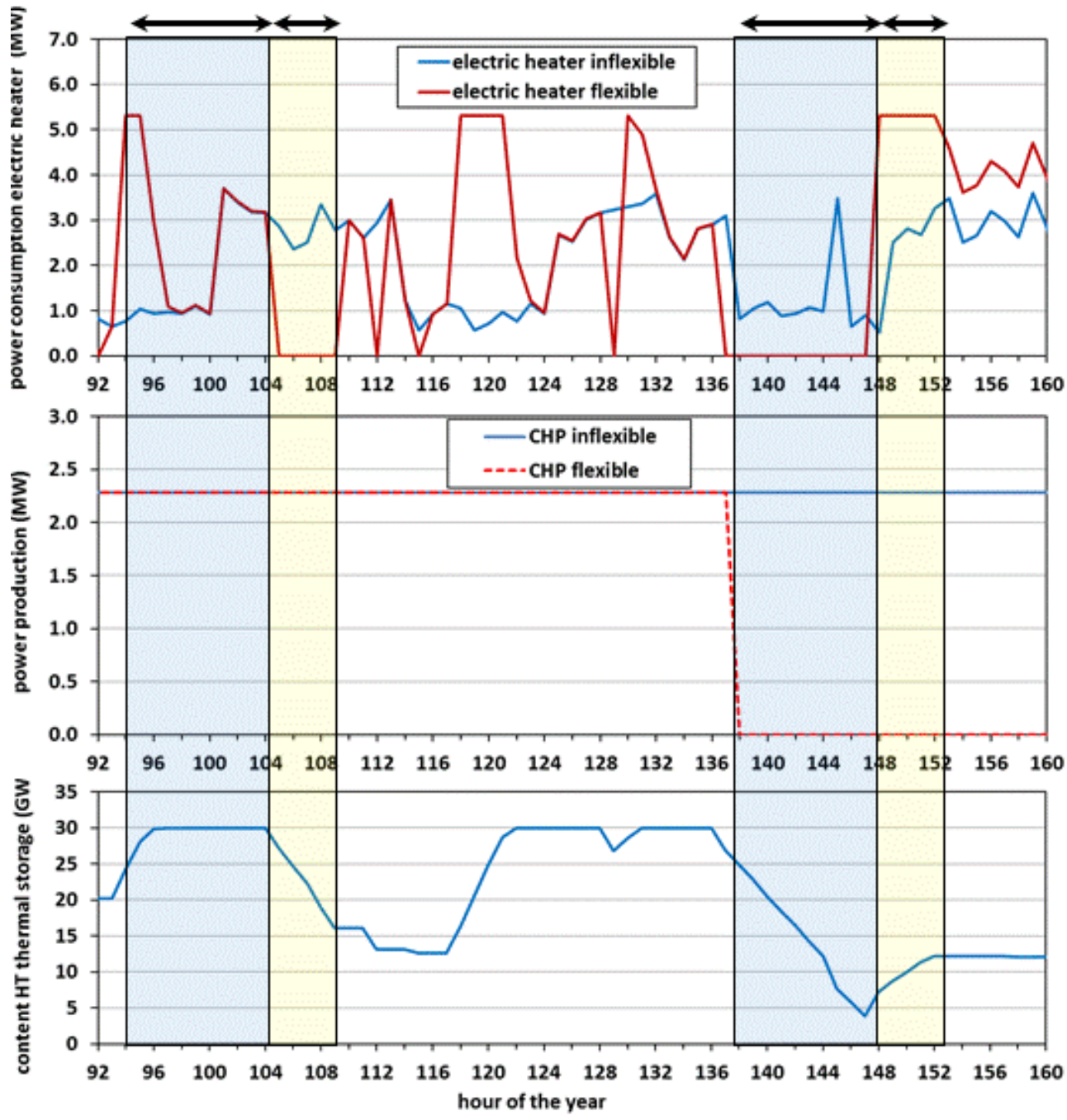

Figure A 5: Illustration of the flexible dispatch of the electric heater (upper panel), the CHP (middle panel) and the filling level of the HT-TES (bottom level).

Figure A 5 illustrates the flexible operation of the CHP plant, the electric heater and the HTTES which provide process heat in the model. 
- During intermediate situations with only a light surplus, the CHP unit is shut off and the process heat demand is entirely provided by the electric heater. (Not shown: During intermediate situations with only a light deficit, the CHP unit runs with nominal load and provides baseload process heat, whereas the electric heater provides the peak load heat demand.

- Before a strong surplus situation, both the electric heater and the CHP unit are shut off. Process heat demand is provided by the HT-TES, in order to empty the storage and to give maximum room for storage charging during the surplus situation.

- During the strong surplus situation, both the electric heater and the CHP unit run on nominal load in order to decrease $t$ local excess power production. Excess process heat is used to charge the HT-TES.

- Before a strong deficit situation, both the electric heater and the CHP unit run on nominal load. Excess heat is stored in the HT-TES. If the storage is full, the CHP unit provides base load heat, whereas the electric heater provides the remaining heat demand.

- During the strong deficit situation, the CHP runs on nominal load (in order to decrease the deficit), whereas the electric heater is shut off (in order not to increase the deficit). Any additional process heat demand not provided by the CHP is taken from the HT-TES.

\section{A6. Sorted annual load curves and full load hours}

Figure A 6 shows sorted annual load curves for all (principally) flexible consumers and the CHP plant in the INFLEX simulations. Furthermore, Figure A 6 documents the full load hours $\left(\mathrm{FLH}^{3}\right)$ for each technology. Figure A 7 shows the respective results for the STD simulations, but also includes the sorted annual load curves and FLH for storage charging and discharging as well as the sorted annual filling state of the storages (HT-TES, LT-TES, and CTES). Furthermore, Figure A 7 documents the equivalent full cycles (EFC) for the storages.
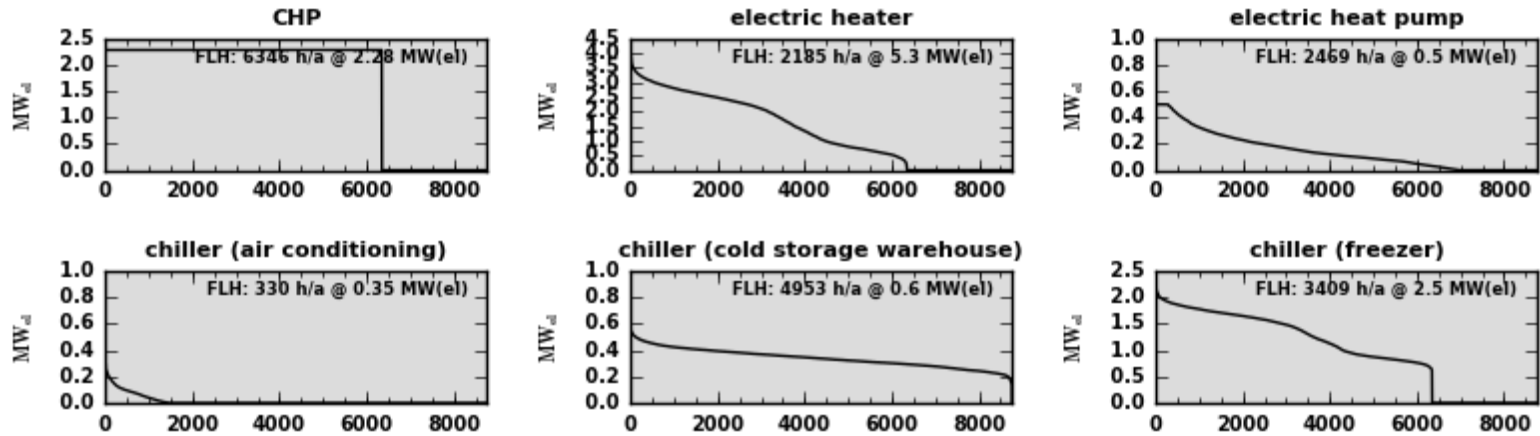

Figure A 6: Sorted annual load curves and full load hours for the (principally4) flexible power consumers and production technologies in the INFLEX simulations. FLH: full load hours; EFC: equivalent full cycles. For definitions: See text.

For all electric consumers (chillers, electric heater, electric heat pump), the full load hours are the annual power consumption $\left(\mathrm{kWh}_{\mathrm{e}} / \mathrm{a}\right)$ divided by the nominal capacity $\left(\mathrm{kW}_{\mathrm{el}}\right)$. For the CHP, the full load hour is calculated as the annual gross power production $\left(\mathrm{kWh}_{\mathrm{el}} / \mathrm{a}\right)$ divided by the nominal capacity $\left(\mathrm{kW}_{\mathrm{el}}\right)$. For the charging (resp. discharging) of the TES, the full load hours are defined as the annual sum of gross storage input $\left(\mathrm{kWh}_{\mathrm{th}} / \mathrm{a}\right)$ (resp. output) divided by the charging (resp. discharging) capacity $\left(\mathrm{kW}_{\text {th }}\right)$. The equivalent full cycles (EFC) for the TES

\footnotetext{
${ }^{3}$ Full load hours are defined as annual power consumption (for the CHP: power production) divided by the nominal electric load of the technology.

${ }^{4}$ Note that in the INFLEX simulations, these technologies are not operated in a flexible manner. 
are defined as the annual total storage input $\left(\mathrm{kWh}_{\mathrm{th}} / \mathrm{a}\right)$ divided by the storage capacity $\left(\mathrm{kWh}_{\mathrm{th}}\right)$. Similar definitions as for HT-TES and LT-TES hold for C-TES.
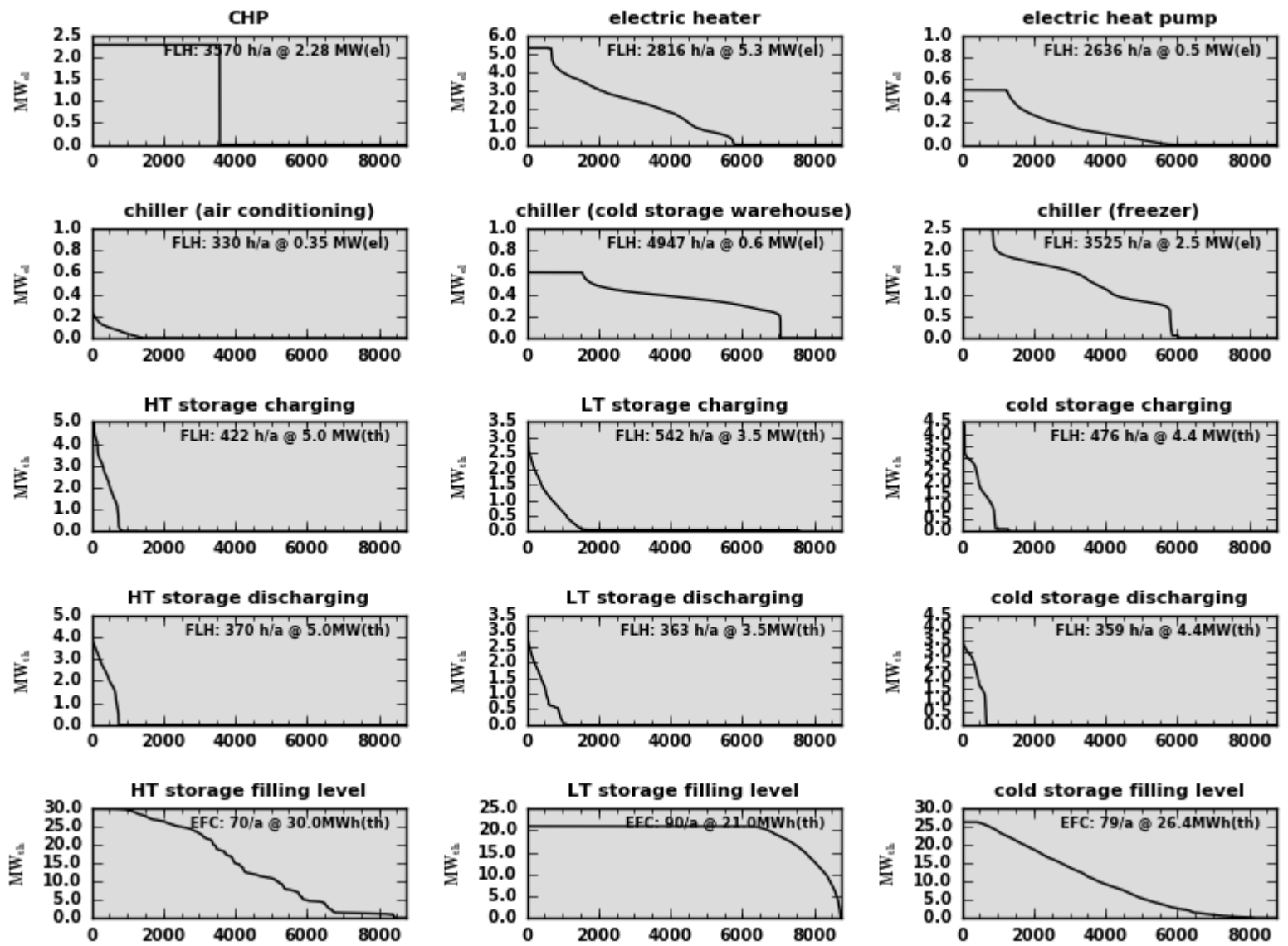

Figure A 7: Sorted annual load curves and full load hours for the flexible power consumer and production technologies, the HT-TES, LT-TES, and C-TES in the STD (=STOR_6H) simulations; FLH: full load hours, EFC: equivalent full cycles. For definitions: See text.

A comparison of Figure A 6 with Figure A 7 shows the following:

- In both the INFLEX and the STD simulations, the CHP unit runs either with nominal load or is shut off. However, if operated flexibly, the full load hours of the CHP decrease significantly from $6346 \mathrm{~h} / \mathrm{a}$ to $3570 \mathrm{~h} / \mathrm{a}$. This can be explained by the fact that during most deficit situations, the CHP is already running on nominal load in the INFLEX case (providing base load process heat). Thus, during deficit situations in the STD simulations, the CHP cannot increase power production any more compared to INFLEX. In contrast, during surplus situations, the CHP is shut off in STD (but not in INFLEX), resulting in significantly lower full load hours in the inflexible case.

- In contrast to the CHP, full load hours of the electric heater increase in the STD case compared with the INFLEX case, as the electric heater has to compensate (on annual basis) the reduced process heat from the CHP in the STD case. Furthermore, the electric heater is running more often on nominal load and is shut off more often in STD than in INFLEX, reflecting the dispatch algorithm for deficit and surplus situations.

- For the chillers and the electric heat pump, the full load hours in the INFLEX and STD case are comparable. This reflects the fact that useful energy demand (provided by the chillers and the heat pump) is identical (or at least similar in the case of the heat pump) in the INFLEX and STD simulations. However, the sorted load duration curves show differences between INFLEX and STD similar to the electric heater. Again, these 
differences reflect the operation strategies during surplus and deficit situations in the STD case compared to INFLEX.

\section{A7. Additional literature}

[1] B. Fricke and S. Steininger, "Die kommunale Effizienzrevolution für den Klimaschutz in den deutschen Städten. Voraussetzungen, Transformationspfade und Wirkungen "KomRev," Solarzeitalter, vol. 27, no. 2, pp. 34-40, 2015

[2] MTU 2017: Hotmodule Brennstoffzelle - MTU Onsite Energy. Availabe from http://www.mtu-online.com/fileadmin/templates/mtu/files/Brennstoffzelle_d.pdf (downloaded March 9th 2017) 